\title{
Katı-Sıvı Ekstraksiyonunda Kullanılan Modern Teknikler ve Bu Teknikler Arasında Ultrason Yardımlı Ekstraksiyonun Yeri
}

\author{
Memnune ŞENGÜL id Elif Feyza TOPDAŞ* \\ Atatürk Üniversitesi, Ziraat Fakültesi, Gıda Mühendisliği Bölümü, Erzurum, Türkiye \\ (*Sorumlu yazar e-mail: efeyza.topdas@atauni.edu.tr) \\ DOI: 10.17097/ataunizfd.466649
}

Geliş Tarihi (Received Date): 02.10.2018

Kabul Tarihi (Accepted Date): 29.03.2019

\begin{abstract}
ÖZ: Son yıllarda biyomoleküller nutrasötik potansiyelleri nedeniyle ilgi çekmekte ve bu bileşenlerin çeşitli doğal kaynaklardan ektraksiyonunda kullanılan tekniklerin geliştirilmesi yönünde yapılan çalışmalar artmaktadır. Bitki hücre duvarında bulunan hemiselüloz, nişasta ve pektin gibi polisakkaritlerin varlığı klasik ekstraksiyon tekniklerinin etkinliğini azaltmaktadır. Ayrıca klasik teknikler; uzun ekstraksiyon süreleri, fazla miktarda çözgen ihtiyacı, düşük ekstraksiyon seçiciliği, yüksek maliyet ve fazla miktarlarda çözgenin buharlaştırılma zorunluluğu gibi olumsuz yönlere de sahiptir. Bu nedenle, biyomoleküllerin etkin şekilde kazanımı için yeşil ve yeni ekstraksiyon tekniklerinin geliştirilmesine ihtiyaç vardır. Günümüzde yaygın olarak kullanılan ultrason uygulaması ile oluşan mikron ebatındaki oyukcuklar hücre duvarında bozunmaya ve parçacık boyutlarında küçülmeye neden olmakta ve böylece kütle transferini hızlandırarak ekstraksiyon oranlarının artmasını sağlamaktadır. Ultrason yardımlı ekstraksiyon, işlem süresini kısalmakla birlikte daha yüksek saflıkta ürün eldesi sağlamakta, enerji sarfiyatını azaltmakta ve daha az çözgen kullanımı ile çevreci bir teknoloji olarak karşımıza çıkmaktadır. Bu derlemede modern ekstraksiyon teknikleri bütünsel bir bakış açısı ile ele alınmakta ve bu teknikler içerinde ultrason yardımlı ekstraksiyonun yeri detaylı olarak ifade edilmektedir.
\end{abstract}

Anahtar Kelimeler: Ekstraksiyon, Ultrason, Ultrason yardımlı ekstraksiyon, Biyomolekül

\section{Modern Techniques Used in Solid-Liquid Extraction and the Place of Ultrasound Assisted Extraction Among These Techniques}

\begin{abstract}
In recent years, biomolecules have attracted attention due to their nutraceutical potentials and studies on development of techniques for the extraction of these components from various natural sources are increasing. The presence of polysaccharides such as hemicelluloses, starch, pectin inside the plant cell wall, reduces the extraction efficiency of conventional extraction techniques. Also, conventional techniques has negative aspects namely, long extraction times, large amount of solvent, low extraction selectivity, high cost and the necessity of solvent evaporation in excess amounts. Therefore, there is a need for the development of green and new extraction techniques for the efficient recovery of biomolecules. By ultrasound application which is a modern extraction technique, micron sized cavites cause degradation in the cell wall and a decrease in particle size and so it accelerates mass transfer and increase the extraction rates. Ultrasonic extraction shortens the processing time and provides a higher product purity, reduces energy consumption and results in an environmentally friendly technology with less solvent usage. In this review, modern extraction techniques are considered from a holistic point of view and the location of the ultrasonic extraction among these techniques is expressed in detail
\end{abstract}

Keywords: Extraction, Ultrasound, Ultrasound assisted extraction, Biomolecule

\section{GİRIŞ}

Seçici çözücüler kullanılarak bitki veya hayvan dokularındaki biyoaktif bileşenlerin inört veya inaktif kısımlardan ayrılmasını içeren işlemler bütünü 'ekstraksiyon' olarak tanımlanmaktadır (Handa et al., 2008). Bitkisel ekstraktlar ise; bitkilerin yaprak, çiçek, tohum, kök veya kabuk kısımlarından bir ekstraksiyon prosedürü uygulanarak elde edilmiş aktif bileşenler veya bileşenlerin karışımı olarak tanımlanabilmektedir. İdeal bir ekstraksiyon yöntemi basit, ucuz, hızlı ve çevreci olmanın yanı sıra istenen bileşenin yüksek verimde elde edilmesini sağlamalıdır (Chemat et al., 2011). Ekstraksiyonda elde edilen biyoaktif bileşenler kayıp ve bozunmaya uğramadan ve ayrıca ilave saflaştırma gerektirmeden elde edilmelidir (Demir, 2015). Kat1 bir maddenin bileşenlerinden birinin veya bir bölümünün uygun bir çözücü kullanarak elde edilmesi prensibine dayanan katı: sıvı ekstraksiyonda verim; çözücü türü, $\mathrm{pH}$, kat1- sıv1 oranları, partikül boyutu, sıcaklık ve süre gibi faktörlerden etkilenmektedir (İlbay, 2016). Bitkisel materyallerden biyoaktif bileşenlerin ekstraksiyonu özellikle kozmetik, bitkisel kaynaklı ilaç ve gıda endüstrilerini ilgilendirmektedir (Vinatoru et al., 2017).

\section{Modern Ekstraksiyon Yöntemleri}

Klasik ekstraksiyonda karşılaşılan; uzun ekstraksiyon süresi, yüksek maliyet, yüksek saflıkta çözgen ihtiyacı, büyük miktarlarda çözgenin buharlaştırılma zorunluluğu, düşük ekstraksiyon seçiciliği ve sicaklığa hassas bileşenlerin termal bozunumu (Chemat, 2017) gibi olumsuzlukların giderilme çabaları, yeni ekstraksiyon tekniklerinin geliştirilmesini sağlamıştır (Azmir et al., 2013). Ultrason yardımlı ekstraksiyon, enzim yardımlı ekstraksiyon, mikrodalga yardımlı ekstraksiyon, 
vurgulu elektrik alanı yardımlı ekstraksiyon, süperkritik akış ekstraksiyonu ile basınçlı sıvı ekstraksiyonu gibi yöntemler modern ekstraksiyon yöntemleri olarak geliștirilmiș olup; bu tekniklerden bazıları, ABD Çevre Koruma Kurumu tarafindan belirlenen standartlara uyduğu için 'yeşil teknikler' olarak adlandırılmaktadır (EPA, 2017). Günümüzde geliştirilen ekstraksiyon tekniklerinde aranan temel özelikler; daha güvenilir kimyasalların kullanımı, enerji verimliliği tasarımı, yenilenebilir hammadde kullanımı, kirliliğin önlenmesi, kısaltılmış ekstraksiyon süresi, düşük maliyet ve kazaların önlenmesi şeklinde sıralanabilmektedir (Wen et al., 2018).

\section{Vurgulu Elektrik Alanı Yardımlı Ekstraksiyon}

Vurgulu elektrik alanı (VEA) son on yılda presleme, kurutma, ekstraksiyon ve difüzyon proseslerinin iyileştirilmesinde yararlı bir yöntem olarak kabul edilmektedir (Barsotti and Cheftel, 1998; Angersbach et al., 2000; Vorobiev et al., 2005; Vorobiev and Lebovka, 2006). VEA'nın temel prensibi, bir seri elektrot arasına yerleştirilen ürüne 1$100 \mu$ s arasında değişen sürelerde elektrik vurguları uygulanarak hücre zarının yapısının parçalanması ve ekstraksiyonun etkinliğinin artırılmasıdır. VEA'a maruz kalan hücrede moleküller dipol özelliklerine dayanarak hücre içerisinde yüklerine göre membran yüzeyinin iki tarafinda birikmektedirler. Biriken yüzey yükleri transmembran potansiyelini ve elektromekanik stresi artırmaktadır. Transmembran potansiyeli yaklaşık 1 Volt'luk kritik bir değeri aştığında membranın zayıf bölgelerinde yük taşıyıcı moleküller arasında itme meydana gelmekte ve porlar oluşmaktadır. $\mathrm{Bu}$ durum geçirgenlik şiddetinin artmasına neden olmaktadır (Azmir et al., 2013). Genelde, bitkilerin ekstraksiyonunda üstel bozunma darbelerine sahip basit devreler kullanılmaktadır. Sistem bitki materyalinin yerleştirildiği iki elektrottan oluşan bir işleme odasına sahiptir. Uygulama odasının tasarımına bağlı olarak VEA sürekli veya kesikli olarak çalışmaktadır (Puértolas et al., 2010). VEA uygulamasının etkinliği; spesifik enerji girişi, vurgu sayısı, uygulama sıcaklığı ve ekstrakte edilecek materyalin özellikleri gibi faktörlere bağlı olarak değişmektedir (Heinz et al., 2003).

VEA uygulaması ile bitki materyalinin zar yapısı parçalanıp yok edilerek ekstraksiyon süresi kısaltılabilmekte ve kütle transferi arttırılabilmektedir. Toepfl et al. (2006) VEA'nın hücre zarı geçirgenliğini artırma özelliğinden yararlanarak; bitki dokusundan hücre içi bileşiklerin salınımını artırmak için kullanmıştır. 500 ile $1000 \mathrm{~V} / \mathrm{cm}^{\prime}$ 'lik orta düzeyde bir elektrik alanında 102-104 saniyede VEA uygulamasının sicaklıkta fazla yükselme olmadan bitki dokusunun hücre zarına zarar verdiği tespit edilmiştir (Fincan and Dejmek, 2002; Lebovka et al., 2002). Bu nedenle, 1sıya duyarlı bileşenlerin degradasyonu VEA uygulaması ile en aza indirilebilmektedir (Ade-Omowaye et al., 2001). Ayrica bu uygulama, sarf edilen enerji ve süreyi azaltmak için klasik ekstraksiyon öncesinde de bir ön işlem olarak uygulanabilmektedir (López et al., 2009).

Fincan et al. (2004), pancar köklerinden betanin ekstraksiyonu için kullanılan VEA işleminin dondurma ve mekanik presleme gibi işlemlere kıyasla daha etkin bir ekstraksiyon gerçekleştirdiğini ileri sürmektedir. Guderjan et al. (2005) ön işlem olarak uygulanan VEA'nın; misirdan fitosterollerin geri kazanımının \%32.4 ve soya fasulyesinden genistein ve daidzein izoflavonoidlerinin geri kazanımının ise \%20-21 oranında arttığını rapor etmiştir. Corralesa et al. (2008) üzüm atıklarından (sap, çekirdek ve kabuk) antosiyaninlerin ekstraksiyonunu gerçekleştirmek için kullandığı birçok yöntem arasında en iyi sonucu VEA yardımıyla bulduğunu belirtmiştir. Benzer şekilde VEA uygulamasının polifenol ve antosiyaninlerin ekstraksiyonunda artış sağladığı Delsart et al. (2012) tarafindan da rapor edilmektedir.

\section{Enzim Destekli Ekstraksiyon}

Bitki matriksindeki bazı fitokimyasallar hücre sitoplazmasında dağılmış halde bulunmakta ve bazı bileşikler rutin bir ekstraksiyon işleminde bir çözücü ile erişilemeyen hidrojen bağları veya hidrofobik bağlar ile polisakkarit-lignin ağında tutulmaktadır (Azmir et al., 2013). Enzimatik ön muamele, bağlı bileşiklerin serbest bırakılması veya genel anlamda verimin artırılması için etkili bir yol olarak görülmektedir (Rosenthal et al., 1996). Selülaz, $\alpha-$ amilaz ve pektinaz gibi spesifik enzimlerin ekstraksiyon esnasında ilavesi, hücre duvarının parçalanmasını sağlamakta ve polisakkaritler ile lipid bileşenlerinin hidrolizini artırmaktadır (Rosenthal et al., 1996; Singh et al., 1999). Enzim yardımlı ekstraksiyon için; enzim yardımlı sulu ekstraksiyon ve enzim yardımlı soğuk presleme olmak üzere iki farklı uygulama söz konusudur (Latif and Anwar, 2009). Enzim yardımlı sulu ekstraksiyon çeşitli tohumlardan yağların ekstraksiyonunda kullanılmak üzere geliştirilmiştir (Hanmoungjai et al., 2001; Rosenthal et al., 1996, 2001; Sharma et al., 2002). Enzim yardıml soğuk presleme sisteminde ise bir polisakkarit- protein kolloidi mevcut olmadığından enzimler tohumların hücre duvarının hidrolizinde kullanılmaktadır (Concha et al., 2004). Bitkinin nem içeriğinin (Dominguez et al., 1995) yanı sıra; enzim kompozisyonu ve konsantrasyonu, bitki materyalinin partikül boyutu, katı:sıvı oranı ve hidroliz süresi gibi parametreler enzim yardımlı ekstraksiyon için kilit faktörlerdir (Niranjan and Hanmoungjai, 2004). Bhattacharjee et al. (2006) enzimlerin toksik olmaması ve tutuşmaz özellikte olmalarından dolayı 
bu ekstraksiyon yöntemini yağlı tohumlardan biyoaktif bileşenlerin ekstraksiyonunda ideal bir alternatif olarak nitelendirmektedir. $\mathrm{Bu}$ yöntemde organik kimyasallar yerine çözücü olarak su kullanıldığından çevre dostu bir teknoloji olarak kabul edilmektedir (Puri et al., 2012).

Gómez-García et al. (2012) tarımsal endüstriyel yan ürünlerden biyoaktif bileşenlerin ekstraksiyonunda enzim kullanımının etkin bir teknoloji olduğunu belirtmektedir. Maier et al. (2008) üzüm posasında 2:1 oranında pektinolitik ve selülolitik enzim karışımını kullanarak fenolik asitler, antosiyanin olmayan flavonoidler ve antosiyaninleri ekstrakte etmiş ve sülfit yardımlı ekstraksiyona kıyasla daha yüksek verim alındığını ifade etmiştir. Ahududu posasından fenolik antioksidanların geri kazanımı amacıyla yapılan bir çalışmada hidro-alkolik ekstraksiyona enzim ilavesinin, enzimatik olmayan kontrole kıyasla daha iyi sonuç verdiği rapor edilmiştir (Laroze et al., 2010).

\section{Mikrodalga Yardımlı Ekstraksiyon}

Mikrodalga yardımlı ekstraksiyon, mikrodalga enerjisi kullanılarak materyalden sıvı içerisinde çözünen bileşenlerin ekstraksiyonunda kullanilabilecek yeni bir yöntem olarak düşünülmektedir (Azmir et al., 2013). Mikrodalgalar $300 \mathrm{MHz}$ ile $300 \mathrm{GHz}$ aralığında bulunan elektromanyetik alanlardır. Mikrodalga yardımlı ekstraksiyon temelde mikrodalgaların polar özellikteki moleküller üzerine etkisine dayanmaktadır (Letellier and Budzinski, 1999). Elektromanyetik enerji iyonik iletim ve dipol dönüş mekanizmalarını takip ederek 1sıya dönüşmektedir (Jain, 2009). İyonik iletkenlik esnasında ortamın akış iyonuna direnç göstermesi sonucu 1sı oluşmaktadır. Diğer taraftan, iyonlar sıkça değişen alan işaretlerine göre yönlerini belirlemekte ve yönergelerin sürekli değişmesi moleküller arası çarpışmalara neden olarak 1S1 üretimine sebep olmaktadır (Azmir et al., 2013).

Mikrodalga yardımlı ekstraksiyon mekanizması Alupului (2012) tarafindan da belirtildiği gibi üç ardışık basamak içermektedir. Birinci basamak, artan sıcaklık ve basınç etkisiyle materyal matriksinin aktif kısımlarından çözünen bileşenlerin ayrılmasını içermektedir. İkinci ve üçüncü basamaklar ise sırasıyla; çözücünün numune matriksi boyunca difüzyonu ve materyal matriksinden çözücüye çözünen bileşenlerin salınımını içermektedir. Bitki materyalinden biyoaktif bileşenlerin ekstraksiyonu için klasik yöntemlere göre daha hızlı 1sıtma, artan ekstraksiyon verimi ve ekipmanların küçüklüğü sistemin avantajlarıdır (Cravottoa et al., 2008). Ayrıca organik çözgen kullanımını azalttığı için mikrodalga yardımlı ekstraksiyon yöntemi çevreci bir teknoloji olarak nitelendirilmektedir (Alupului, 2012). Pan et al. (2013) yeşil çay yapraklarından polifenollerin ve kafeinin ekstraksiyonu için uyguladıkları mikrodalga yardımlı ekstraksiyon işleminde oda sicaklığında 20 saatte uyguladıkları diğer ekstraksiyon yöntemlerinden daha yüksek verim elde ettiklerini belirtmektedirler. Dhobi et al. (2009) Silybum marianum'dan flavolignin ve silybinin bileşiklerini mikrodalga yardımlı ekstraksiyonun yanı sıra; soxhlet ve maserasyon gibi klasik ekstraksiyon teknikleri ile de gerçekleştirmiş ve en yüksek verimi mikrodalga yardımlı ekstraksiyon ile elde etmişlerdir. Asghari et al. (2011) çeşitli bitkilerden sinemaldehit ve tanenin de içerisinde bulunduğu bazı biyoatif bileşenlerin mikrodalga yardımlı ekstraksiyon yöntemi ile klasik yöntemlere göre daha hılı ve kolay bir şekilde ekstrakte edildiğini rapor etmişlerdir. Wei et al. (2019), yalancı iğde (Hippophae rhamnoides L.)'den mikrodalga yardımlı ekstraksiyon ile elde ettikleri polisakkaritlerin in vitro ve in vivo antioksidan aktivitelerini değerlendirmişlerdir. Araştırmacılar, optimum polisakkarit ekstraksiyonunun $600 \mathrm{~W}$ mikrodalga gücü, 6 dakika, 10:1 sıvı:katı oranı ile $85^{\circ} \mathrm{C}$ sıcaklıkta elde edildiğini ve ayrıca $600 \mathrm{~W}$ mikrodalga gücünün yüksek verimde antioksidan polisakkarit salınımını sağladığını bildirmişlerdir. Mikrodalga yardımlı ekstraksiyon ile ultrason yardımlı ekstraksiyon yöntemlerinin kıyaslandığı bir çalışmada ise, misket limonu (Citrus aurantiifolia) kabuklarından doğal fenolik bileşiklerin eldesinde; mikrodalga yardımlı ekstraksiyona kiyasla ultrason yardımlı ekstraksiyonun doğal antioksidan ekstraktlarının eldesinde daha etkili olduğu ortaya koyulmuştur (Rodsamran and Sothornvit, 2019).

\section{Basınçlı Sıvı Ekstraksiyonu}

1996 yılında Richter ve arkadaşları tarafindan bulunan yöntem günümüzde hızlandırılmış sıvı ekstraksiyonu, gelişmiş çözücü ekstraksiyonu veya yüksek basınçlı çözgen ekstraksiyonu gibi isimlerle bilinmektedir (Nieto et al., 2010). Basınçlı sıvı ekstraksiyonu çözücünün kaynama noktasının çok üzerinde ortamda çözücü kalması için yüksek basınç uygulamasıdır (Azmir et al., 2013). Uygulanan yüksek basınç, ekstraksiyonu kolaylaştırmaktadır. Bu teknik yüksek basınç ve sıcaklık kombinasyonu sayesinde az miktarda çözgen gereksiniminin yanı sıra hızlı bir ekstraksiyon da sağlamaktadır. Yüksek ekstraksiyon sıcaklığı, çözünürlük ve kütle transferini arttırırken çözücülerin viskoziteleri ve yüzey gerilimlerini düşürerek daha yüksek analit çözünürlüğünü sağlamakta ve böylece ekstraksiyon verimini arttırmaktadır (Ibañez et al., 2012).

Yöntem, klasik soxhlet ekstraksiyonu ile kıyaslandığında çözgen ve zaman kullanımını belirgin şekilde düşürdügü tespit edilmiştir (Richter et al., 1996). Wang and Weller (2006)'ya göre, basınçlı sıv1 ekstraksiyonu tekniği çevresel matrikslerden yüksek sicaklıklarda stabil olan organik kirleticilerin 
uzaklaştırılmasında da etkin şekilde kullanılmaktadır. Ibañez et al. (2012) basınçlı sivı ekstraksiyonu yöntemini deniz süngerlerinden biyoaktif bileşenlerin ekstraksiyonunda kullanmış ve etkin sonuçlar aldığını rapor etmiştir. Ayrıca, aynı araştırmacılar organik çözücü kullanımının oldukça düşük olması nedeniyle yöntemin çevreci bir ekstraksiyon uygulaması olduğunu belirtmişlerdir. Basınçlı sıvı ekstraksiyonu biyoaktif bileşenlerin ekstraksiyonunda başarıyla uygulanan bir yöntemdir. Optimize edilmiş şartlarda bu yöntem ile soya fasulyesinden izoflavonların ekstraksiyonu degradasyon olmaksızın gerçekleştirilmiştir (Rostagno et al., 2004). Shen and Shao (2005) tütünden terpenoidler ve sterollerin ekstraksiyonunu basınçlı sıvı ekstraksiyonunun yanı sira soxhlet ekstraksiyonu ve ultrason yardımlı ekstraksiyon yöntemleri ile gerçekleştirmiştir. Araştırmacılar verim, tekrarlanabilirlik, ekstraksiyon süresi ve çözücü kullanımı dikkate alındığında ultrason yardımlı ekstraksiyon yöntemine göre basınçlı sıvı ekstraksiyonunun daha az etkili olduğunu ancak, klasik ekstraksiyon yöntemlerine iyi bir alternatif olabileceğini rapor etmişlerdir. $\mathrm{Bu}$ araştırmanın aksine; Mroczek and Mazurek (2009) lycorine ve galanthamine alkoloidlerinin ekstraksiyonunda basınçlı sıvı ekstraksiyonu şartlarını optimize etmiş ve sonuçların sıcak çözgen ekstraksiyonu, mikrodalga yardımlı ekstraksiyon ve ultrason yardımlı ekstraksiyon yöntemlerine k1yasla daha verimli olduğunu vurgulamışlardır. Luthria (2008) maydanoz bitkisinden fenolik bileşiklerin basınçlı sıvı yardımlı ekstraksiyonu üzerine sıcaklık, basıç̧, parçacık boyutu, süre ve numune: çözücü oranı gibi parametrelerin oldukça etkili olduğunu belirlemiştir. Basınçlı sıvı ekstraksiyonu ayrıca propolisten kateşin, gallokateşin, epikateşin gallat, kafeik asit ve klorojenik asit gibi fenolik bileşiklerin ekstraksiyonunda da kullanılmaktadır (Erdogan et al., 2011).

\section{Süperkritik Akışkan Ekstraksiyonu}

Doğada maddeler katı, sıvı veya gaz halinde bulunmaktadır. Süperkritik durum ayırt edici bir hal olup, ancak bir maddenin kritik noktanın üstünde sıcaklık ve basınç altında tutulması ile erişilebilmektedir. Kritik nokta, karakteristik sıcaklık ve basınç değerlerinin üzerinde olan ve maddenin ayırt edici gaz ve sıvı fazların mevcut olmadığı noktadır (Inczedy et al.,1998). Süperkritik durumda gaz ve/veya sıvının spesifik özellikleri ortadan kalktığı için sıcaklık ve basınç değiştirilerek süperkritik akışkan asla sıvılaştırılamamaktadır (Azmir et al., 2013). Süperkritik akışkan gaz benzeri difüzyon, viskozite ve yüzey gerilimi özellikleri ile; sıvı benzeri yoğunluk ve çözünme gücü özelliklerine sahiptir. Bu özellikler, bileşiklerin daha yüksek verimle ekstraksiyonunu sağlamaktadır (Sihvonen et al., 1999).

Basit bir süperkritik akışkanlı ekstraksiyon sistemi; mobil fazlı bir tank, genelde akışkan olarak $\mathrm{CO}_{2}$, gazın basınçlandırılması için bir pompa, yardımcı çözgen, çözücü kap ve pompa, ekstraksiyon kabının içerisine konacağı bir fırın, içerideki yüksek basıncın ölçülmesi ve muhafazası için bir kontrol cihazı ve bir yakalama ünitesinden oluşmaktadır. Genellikle, kuru/1slak gaz sayacı gibi farklı tipte sayaçlar da sisteme bağlanabilmektedir (Azmir et al., 2013).

Karbondioksit, süperkritik akışkan ekstraksiyonunda kullanılan ideal çözgendir. Bu çözgen için kritik sıcaklık oda sıcaklığına yakın $\left(31^{\circ} \mathrm{C}\right)$ ve düşük kritik basınç 74 bar olmakla birlikte genelde sistem 100-450 bar arası 1lımlı basınçlarda çalışma imkânı sunmaktadır (Temelli and GüçlüÜstündag, 2005). Karbondioksitin tek dezavantajı lipidler ve yağlar gibi polar olmayan maddeler için ideal olmasına rağmen düşük polaritesinden dolayı çoğu farmasötikler ve ilaç örnekleri için uygun olmamasıdır. Bu olumsuz durum kimyasal modifiye edicilerin kullanımı ile giderilmektedir (Lang and Wai, 2001; Ghafoor et al., 2010).

Bitkilerden biyoaktif bileşenlerin süperkritik akışkan yardımıyla ekstraksiyonunda verimi etkileyen başlıca değişkenler; sıcaklık, basınç, parçacık boyutu, besleme materyalinin nem içeriği, ekstraksiyon süresi, $\mathrm{CO}_{2}$ akış hızı ve çözgen: numune oranıdır (Temelli and Güçlü-Üstündag, 2005; Ibañez et al., 2012).

Son 10 yılda popüler hale gelmiş olan süperkritik akışkan ekstraksiyonu yaprak, çiçek, tohum, meyve gibi materyallerden etken bileşenlerin ekstraksiyonunda sıklıkla kullanılmaktadır. Süperkritik akışkan ekstraksiyonun klasik ekstraksiyon yöntemlerine göre birçok avantaj1 bulunmaktadır: Süperkritik akışkan, diğer sıvı çözülere göre daha yüksek difüzyon katsayısına ve daha düşük viskozite ile yüzey gerilimine sahip olduğundan numune matriksine daha fazla nüfuz etmekte ve klasik yöntemlerle kıyaslandığında ekstraksiyon süresini önemli ölçüde azaltmaktadır. Süperkritik akışkan numuneye tekrar tekrar geri gönderilerek tam bir ekstraksiyon sağlanmaktadır. Klasik ekstraksiyon yöntemlerinde çözünen maddenin çözücüden ayrılması oldukça zaman alıcı bir işlemdir. Süperkritik akışkan ekstraksiyonunda ayrılma süreci akışkan basıncının düşürülmesi ile kolaylıkla kısaltılabilmektedir. Süperkritik akış ekstraksiyonunda oda sıcaklığında çalışıldığından sıcaklığa karşı hassas bileşenlerin ekstraksiyonu için ideal bir yöntemdir. Klasik ekstraksiyon yöntemlerine kıyasla daha az örnekle çalışılabilmektedir. Az miktarda organik çözücü kullanıldığından yöntem çevre dostu olarak nitelendirilebilmektedir. Süperkritik akışkanın geri kazanımı mümkündür ve 
böylece atık oluşumu en aza indirgenmektedir (Lang and Wai, 2001).

Süperkritik akışkan ekstraksiyonunun en büyük dezavantajı ise; $80 \mathrm{~atm}$ üzerindeki yüksek basınçta çalışılmasından dolayı sistemin yatırım maliyetinin yüksek oluşudur. Diğer dezavantajı ise saf olarak nitelendirilen $\mathrm{CO}_{2}$ tüplerinin içerisinde dahi bulunan \%1-2 oranındaki oksijenin, oksidasyona duyarlı antioksidanlar gibi bileşenler ile tepkimeye girerek düşük miktarda da olsa bozunmalarına sebep olmasidir (Cocero et al., 2000).

Süperkritik akışkan ekstraksiyonunun kullanıldığı çalışmalardan biri, İçen ve Gürü (2010) tarafından çayın sap ve lif atıklarından kafeinin ekstraksiyonu üzerinedir. Araştırmacilar maksimum kafein verimini $14.95 \mathrm{mg} / \mathrm{g}$ çay sapı atığı ve 18.92 $\mathrm{mg} / \mathrm{g}$ çay lifi atığı olarak rapor etmişlerdir. Civanperçeminden esansiyel yağ ekstraksiyonunun gerçekleştirildiği bir çalışmada, akışkan olarak $\mathrm{CO}_{2}$ kullanılarak $10 \mathrm{Mpa}$ basınç ve $40-60^{\circ} \mathrm{C}$ sıcaklıkta süperkritik akışkan ekstraksiyonu uygulanmıştır. Elde edilen esansiyel yağın kamfor, 1,8-kineol, bornil asetat, terpinen ve terpinolen içerdiği saptanmıştır (Bocevska and Sovov'a., 2007). Kavoura et al. (2019), adaçayı (Salvia fruticosa)'nın süpekritik karbondioksit ekstraksiyonunda $60^{\circ} \mathrm{C}$ sicaklıkta 100 bar ile 280 bar arası uygulanan basıncın ekstraksiyon verimini $\% 5.2$ ile $\% 10.3$ aralı̆̆ında değiştirdiğini ve basınç arttıkça ekstraksiyon veriminin arttığını rapor etmişlerdir. Farklı bir çalışmada ise, Xu et al. (2011) polenden süperkritik karbondioksit ekstraksiyonu ile yağ, karotenoid, skualen ve steroller (kampesterol, stigmasterol, $\beta$-sitosterol ve $\beta$-amyrin) ekstrakte etmiş ve maksimum verimi $38.2 \mathrm{Mpa}$ basınç ve $49.7^{\circ} \mathrm{C}$ 'de belirlemiştir.

\section{Ultrason Yardımlı Ekstraksiyon}

Ultrason yardımlı ekstraksiyon yöntemi, elastik bir ortamda yayılan mekanik dalgalar olan ultrasonik dalgaları kullanarak bitki hücre duvarında bozunmayı sağlayan ve kütle transferini hızlandırarak istenen biyoaktif bileşenlerin klasik tekniklere kıyasla daha kısa sürede ve daha yüksek verimle elde edilmesini sağlayan bir tekniktir. Ayrıca, daha düşük enerji sarfiyatı ve daha az çözgen kullanımı ile çevreci bir teknoloji olarak karşımıza çıkmaktadır (Vilkhu et al., 2008; Jadhav et al., 2009). 2010 yllından beri popülerlik kazanan ultrason yardımlı ekstraksiyon yöntemi günümüzde de sıklıkla kullanılmaktadır (Poongothai et al., 2010; Dabre et al., 2011; MárquezSillero et al., 2013; Gliszczy'nska-Swigło et al., 2015; Benkerrou et al., 2018; Kurek et al., 2018).

\section{Ultrason yardımlı ekstraksiyonun etki} mekanizması

Ultrasonik dalgalar ilk olarak, 1881 yılında sodyum potasyum tartarat tetrahidrat kristalinin belirli bir düzlemine alternatif bir voltaj uygulanması ve titreşim oluşumu ile elde edilen piezoelektrik etki ile üretilmiştir. Bunun dışında manyetostriktif yöntemler kullanılarak da ultrasonik dalgalar üretilebilmektedir (Mackersie et al., 2005). Salınımlı ses dalgaları olan ultrasonik dalgaların diğer ses dalgalarından farkı frekans aralığıdır. İnsanların algılayabildiği ses dalgaları $16 \mathrm{~Hz}$ ile $16-20 \mathrm{kHz}$ arasında iken; insanların duyma eşiğinin üzerinde fakat mikrodalga frekansının altında olan ultrasonik dalgalar $20 \mathrm{kHz}$ ile $10 \mathrm{MHz}$ aralığında yer almaktadır (Chemat et al., 2011).

Gıda bilimi ve teknolojisinde kullanılan ultrasonik dalgalar frekans ve yoğunluklarına göre iki gruba ayrılmaktadır. Yüksek frekanslı ultrason (tanısal ultrason) $100 \mathrm{kHz}$ 'in üzerinde olup düşük yoğunluğa sahiptir. Gıdaların kalite kontrolü ve fizikokimyasal özelliklerinin belirlenmesinde kullanılır ve tahrip edici değildir. Yüksek enerjili ultrason (yüksek yoğunluklu ultrason) ise $20 \mathrm{kHz}$ ile $40 \mathrm{kHz}$ aralığında değişen düşük frekansta ve yüksek yoğunlukta olan ultrasondur (Feng and Yang, 2011). Ortama salınan daha şiddetli ses salınımının eşlik ettiği yüksek enerji, mekanik etkiyi artırıp ısı ve kütle transferini hızlandırmakta ve gıda endüstrisi açısından uygulamayı daha etkin hale getirmektedir (Wang et al., 2018).

Ultrasonik dalgalar da diğer ses dalgalarına benzer şekilde, bir ortamdan geçerken parçacıkların boylamasına yer değiştirmelerinden dolayı (Mason, 1990) sıkıştırma ve gevşeme fazlarının oluşmasına sebep olmaktadır (Vinatoru et al., 2017). Ortamda piston görevi gören ses dalgası kaynağında piston açık pozisyonda iken sıkıştırma fazı oluşurken, kapalı konumda olduğunda gevşeme fazı meydana gelmektedir. Gevşeme fazı esnasında, büyüklüğü sıvının niteliği ve saflığına bağlı olan negatif bir basınç oluşmakta ve bu basınç molekülleri ayrı ayrı çekmektedir (Suslick, 1989; Mason and Lorimer, 2002). Gevşeme fazından tamamen farklı olan sıkıştırma fazında ise, sıvı fazı oluşturan moleküller geçici olarak yerlerinden koparak çevredeki diğer moleküllerle çarpışabilmektedirler (Chemat et al., 2017). Bir ses dalgası yeterince yüksek yoğunlukta ise gevşeme fazında kuvvetler arası çekim gücü aşılabilmekte ve sıvı içerisinde boşluklar meydana gelmektedir (Mason and Lorimer, 2002). Oluşan boşluklar 'kavitasyon kabarckkları' olarak adlandırılmaktadır. Kararlı ve geçici kabarcıklar olarak iki şekilde sınıflandırılan kabarcıklardan kararlı olanlar; birçok sıkıştırma-gevşetme döngüsüne maruz kalarak bir denge boyutu etrafında çoğunlukla lineer olmayan bir şekilde salınmaktadırlar. Geçici kabarcıklar ise, bir veya birkaç döngü sonrası başlangıç büyüklüğünü iki katına çıkarmaktadırlar (Mason and Lorimer, 2002; Leong et al., 2011). Büyüme, geçici kabarcığın gevşeme fazında ortamdaki çözünmüş halde bulunan buhar ve gazları 
içerisine alması ve sıkıştırma fazında dışarı atamamasından kaynaklanmaktadır (Ashokkumar, 2011). Kritik büyüklüğe ulaşan kabarcıklar şiddetle çökmekte ve bu sırada yaklaşık 50-1000 atm basınç (Suslick 1999) ile $5000 \mathrm{~K}$ civarında sıcaklık (Flint and Suslick, 1999) açığa çıkarak geçici sıcak noktalar oluşmaktadır (Flint and Suslick, 1999). Oluşan sıcak noktalar kimyasal reaksiyon hızını önemli ölçüde artırmaktadır (Suslick et al., 1999). Kabarcıkların katı materyal yüzeyinde çöküşü sonucu ortamda sıcaklık ve basıncın yükselmesi mikrojetlerin oluşmasını sağlamaktadır. Mikrojetler yüzeyde soyulma, erozyon, hücre duvarının yıkımı ve hücre içeriğinin dışarı sızmasına neden olmakta ve böylece çeşitli kaynaklardan doğal bileşiklerin ekstraksiyonu sağlanmaktadır (Awad et al., 2012; Picó, 2013).

Son yıllarda gıda, kozmetik ve ilaç endüstrileri açısından önemli olan biyoaktif bileşiklerin ekstraksiyonunda ultrason yardımlı ekstraksiyon yönteminin kullanımı üzerine yapılmış birçok çalışma mevcuttur (Caldeira et al., 2004; Xia et al., 2006; Chen et al., 2007; Barbero et al., 2008; Ma et al., 2009; Virot et al., 2010; Canales et al., 2017; Zhu et al.,2017; Caleja et al., 2017; Chen et al., 2018; Nipornram et al., 2018). Limonium sinuatum çiçeklerinden doğal antioksidanların ekstraksiyonu üzerine yapilan bir çalışmada; klasik ekstraksiyon tekniklerinden maserasyon ve soxhlet yöntemlerine göre ultrason uygulamasinın antioksidan aktivite ve ekstraksiyon verimini artırdığ 1 , ekstraksiyon süresini ise önemli ölçüde kısalttığı bildirilmiştir (Xu et al., 2017). Ma et al. (2009) ve Salar Bashi et al. (2012) ultrason yardımlı ekstraksiyonun modern yönemlerden mikrodalga yardımlı ekstraksiyon ve süperkritik akışkan ekstraksiyonuna kıyasla daha ucuz olduğunu ve uygulamanın daha kolay olduğunu rapor etmektedir. Ma et al. (2008) ve Hossain et al. (2012) ultrason yardımlı ekstraksiyon ile elde edilen fenolik maddelerce zengin ekstraktlarda antioksidan aktivitenin yüksek olduğunu bildirmişlerdir. Keten tohumlarından lignan ve bazı fenolik maddelerin ekstraksiyonununda kullanılan ultrason yardımlı ekstraksiyon yönteminin musilaj oluşumunda azalma ve ekstraksiyon verimini artırdığı çalışma da ultrason uygulamasının kütle transferini hızlandırdığını göstermektedir (Corbin et al., 2015). Hammi et al. (2015) Zizyphus lotus meyvesi için en iyi antioksidan aktivitenin sağlandığ 1 ekstraksiyon koşulunu $63^{\circ} \mathrm{C}$, $\% 50$ etil alkol konsantrasyonunda, 25 dak, $67 \mathrm{ml} / \mathrm{g}$ çözücü/katı materyal oranı ile ultrason yardımlı ekstraksiyon işlemi olarak bildirmiştir. Caleja et al. (2017) Melissa officinalis L.'den rosmarinik asit, Machado et al., (2017) Eugenia brasiliensis, Rubus fruticosus ve Vaccinium myritillus'dan antosiyaninler, Velickovic et al. (2017) Erica carnea L.'den tannin, gallotanninler ve antosiyaninler, Carrillo et al. (2017) Satureja macrostema'dan fenolik bileşenlerin ekstraksiyonunda kullanmış oldukları ultrason yardımlı ekstraksiyon işleminin etkinliğini vurgulamışlardır. Herrera and Luque de Castro (2004), uyguladıkları yarı otomatik ultrasonik yöntem (0.8 saniye aralıklı olarak toplam 30 saniye) ile çilek meyvesinden rutin, naringin, naringenin, kuersetin, elajik asit ve kaempferol gibi fenolik bileşikleri etkin şekilde ekstrakte ettiklerini rapor etmişlerdir. Benzer şekilde, çalışmalarında ultrason yardımlı ekstraksiyon yöntemini kullanan Yang and Zhang (2008) Euonymus alatus (Thund.) Sieb yapraklarından rutin ve kuersetinin, Li et al. (2005) ise Eucommia ulmodies Oliv.'in taze yaprak, taze kabuk ve kurutulmuş kabuklarından klorojenik asidin diğer yöntemlere kıyasla daha yüksek verimle kazanımının sağlandığını bildirmiştir. Yang et al. (2018) ise ultrason yardımlı ekstraksiyon uygulamasını pirinçten protein ekstraksiyonunda kullanmış ve ultrasonun verim, ürün saflığı ve modifiye edici özellikleri artırdığını bildirmiştir.

Ultrason yardimlı ekstraksiyonun bitkilerden bahsedilen biyoaktif bileşiklerin dişında aroma maddeleri (Caldeira et al., 2004; Xia et al., 2006; Canales et al., 2017; Santos et al., 2019), mineral maddeler (Santos et al. 2017) ve özellikle doğal renk maddelerinin (Shen et al., 2014; Joaquín-Cruz et al., 2015; Zhang and Wang, 2017; Machado et al., 2017; Pinela et al., 2019) ekstraksiyonunda da yaygin olarak kullanıldığı görülmektedir. Yolmeh et al. (2014) annotto tohumundan ekstrakte ettikleri renk maddelerinin ultrason yardımlı ekstraksiyon yöntemi ile en yüksek verimde elde edildiğini ifade etmiştir. Sivakumar et al. (2009) farklı bitkilerden; Leungo et al. (2014) ise domatesin kabuk, tohum ve pulpundan ultrason yardımlı ekstraksiyon yöntemi ile ekstrakte edilen doğal renk maddelerinin sırasıyla; \%13-\%100 arasında ve \%143 oranında artan verimle elde edildiğini bildirmişlerdir. Ancak, yapılan literatür taramasında yukarıda ifade edilen araştırma sonuçlarının aksini bildiren çalışmaların da mevcut olduğu görülmüştür. Zhao et al. (2006) (all-E)astaksantin karotenoidinin, Biesaga (2011) ise mirisetin, kuersetin, kamferol, ramnetin gibi flavonoidlerin ultrason uygulaması ile degrade olduklarını ve ayrıca ultrasonik güç ve uygulama süresi artışının degradasyonda artışa neden olduğunu bildirmişlerdir. Benzer sonuçları tespit eden D'alessandro and Dimitrov (2014) da Aronia melanocarpa atık kısımlarından ultrason yardımlı antosiyanin ekstraksiyonunda elde edilen onyedi polifenolik bileşiğin düşük sıcaklıkta daha yüksek verimle elde edildiğini belirtmiştir.

\section{Ultrason yardımlı ekstraksiyonu etkileyen parametreler}

Ultrason yardımlı ekstraksiyonun başarılı bir şekilde uygulanabilmesi için çeşitli işlem 
değişkenlerinin detaylı olarak açıklanması gerekmektedir. Uygulanan işlem parametreleri ekstraksiyonu önemli düzeyde etkilemekte ve ekstraksiyon verimini değiştirmektedir. Ancak, verimin her zaman ekstraksiyon sürecinin tek hedefi olmadığını da düşünmek gerekmektedir. Uygulanan yöntemin temiz, yeşil ve sürdürülebilir olması da dikkate alınması gereken faktörlerdir. Sistemin tasarımı, ekstraksiyon süreci parametreleri, elektrik tüketimi, çözücü tipi ve matriks parçacıklarının boyutu bu faktörler arasında sayılabilmektedir (Capelo-Martınez et al., 2004; Santos and Capelo 2007; Shirsath et al., 2012). Ultrasonik dalgaların frekans, dalga boyu ve genlik gibi özellikleri akustik kavitasyonu ve dolayısıyla ekstraksiyonu etkilemektedir. Güç girişinin yanı sıra reaktör tasarımı ve prob şekli de süreci etkileyen faktörler arasındadır (Pingret et al., 2013). Ultrason yardımlı ekstraksiyonu etkileyen parametreler fiziksel parametreler ve ortam ile ilgili parametreler olmak üzere iki kategori altında ele alınmıştır:

\section{a. Fiziksel parametreler}

Güç ve sıcaklık: Sonokimyasal bir süreçte uygulanan akustik güç enerjisinin her zaman rapor edilmese de; doğrudan veya dolaylı olarak ölçülmesine izin veren bazı fiziksel yöntemler mevcuttur. $\mathrm{Bu}$ yöntemler, ultrasonik dalgaların uygulanmasının ardından ortamdaki fiziksel ve kimyasal değişiklikleri ölçerek artan enerjiyi tahmin etmektedir. Akustik basıncın ölçülmesinde en yaygın kullanılan fiziksel yöntemler hidrofon ve optik mikroskoplar kullanılarak gerçekleştirilen alüminyum folyo yöntemi ve kolorimetrik yöntemdir (Margulis and Margulis, 2003). Kavitasyon kabarcıklarının çöküşü sonrası oluşan $\mathrm{OH} \bullet$ radikallerinin indirekt ölçümü de kullanılmakta olan kimyasal bir yöntemdir (Suslick et al., 2011). Birçok çalışma, yüksek ultrasonik gücün kesme kuvvetini artırdığını ve materyalde büyük değişikliklere neden olduğunu göstermektedir. Ancak, g1da endüstrisinde bu parametre en iyi sonucu elde etmek ve minimum güç kullanmak için optimize edilmiştir (BermúdezAguirre et al., 2011). Genelde, ultrason yardımlı ekstraksiyonda en yüksek verimlilik ultrason gücünün artırılması, çözücü-katı temasını artırmak için gıdanın nem içeriğinin azaltılması ve ekstraksiyon süresini kısaltacak şekilde sıcaklığın ayarlanması ile gerçekleştirilmektedir (Chemat et al., 2017).

Seçilen ultrason frekansı da ekstraksiyon işlemini etkileyen faktörler arasındadır. Frekans, kabarcık rezonans boyutunu etkilemektedir. En çok kullanılan frekans aralığı $20 \mathrm{kHz}$ ile $100 \mathrm{kHz}$ arasıdır. Ultrason yardımlı ekstraksiyonda daha yüksek frekansların kullanımı sadece birkaç çalışmada incelenmiştir. Toma et al. (2001) 20 kHz'e kıyasla uyguladıkları diğer yüksek frekans aralıklarının
Calendula officinale yapraklarının yapısı üzerinde ultrasonun fiziksel etkilerini azalttığını rapor etmiştir. İlginç şekilde, Chukwumah et al. (2009) fistık üzerine yaptığı bir çalışmada uygulanan frekansa göre ekstrakte edilen fenolik bileşenlerin değiştiğini 25 $\mathrm{kHz}$ 'de daidzein ve genistein elde ederken, $80 \mathrm{kHz}$ 'de biyokanin A ve trans-resveratrolün ekstrakte edildiğini bildirmiştir. Ancak $80 \mathrm{kHz}$ frekansta gerekli ekstraksiyon süresinin uzadığına dikkat çekilmiştir. González-Centeno et al. (2014) üzüm posasından fenoliklerin ekstraksiyonu amaciyla 40, 80 ve $120 \mathrm{kHz}$ olmak üzere 3 farklı frekans uygulamış ve en etkin frekansın $40 \mathrm{kHz}$ olduğunu rapor etmişlerdir.

Ultrason frekansı arttıkça Sıv1 içerisinde kavitasyon üretimi ve dolayısıyla kavitasyon yoğunluğu azalmaktadır (Mason and Lorimer, 2002). Yüksek frekansta akustik kavitasyonun gerçekleşmesi oldukça zordur. Çünkü kavitasyon baloncukları gevşetme çevrimi esnasında eski haline dönebilmek için bir miktar süreye ihtiyaç duymaktadır ve bu süre yüksek frekansta azalacağı için kavitasyon kabarcıkları yeterince büyüyemeyecektir. Gevşeme fazının süresi ultrasonik frekans ile ters orantılıdır. Bu nedenle yüksek frekansta kavitasyon oluşturmak için daha büyük genlik değerleri gereklidir (Mason and Lorimer, 2002).

Düşük frekanslarda, geçici kavitasyon kabarcıkları göreceli olarak daha az sayıdadır ancak kabarcık çapları büyüktür ve kimyasal etkilerindense fiziksel etkileri daha fazladır (Leong et al., 2011, Mason et al., 2011).

Yoğunluk: Ultrasonik yoğunluk, saniyede metrekare emisyon yüzeyi için iletilen enerji olarak tanımlanmaktadır (Tiwari et al., 2015). Bu parametre transdüser genliği ve dolayısıyla ses dalgasının basınç genliği ile doğrudan ilişkilidir (Santos et al., 2009). Basınç genliğinin artması kabarcık çöküşünün şiddetini artırmaktaktadır. Kavitasyon eşiğini aşmak için minimum bir ultrasonik yoğunluk değeri gereklidir. Ultrason yoğunluğu ekstraksiyon verimini etkileyen önemli faktörlerdendir. Yoğunluktaki artış sonokimyasal etkilerin de artışına neden olmaktadır (Mason and Lorimer, 2002). Genliğin (amplitüd) artması ultrason yoğunluğunu arttırıp kavitasyon yerine sıvının karışmasına ve dolayısıyla zayıf ultrason iletimine sebep olarak ultrasonik transdüserin hızla bozulmasına neden olabilmektedir. Ancak, yăg gibi yüksek viskoziteli sıvılarla çalışılırken genlik değeri artırılmalıdır (Santos et al., 2009).

Wang et al. (2015) ultrason yardiml ekstraksiyon ile pektin eldesi üzerine yapmış oldukları çalışmada, $20 \mathrm{kHz}$ frekansta ultrasonik yoğunluk değerini 10.18-14.26 W/ $\mathrm{cm}^{2}$ olarak belirlemişlerdir. Ancak, Chemat et al. (2017)' de bu yoğunluk değerinin optimizasyona tabi tutulması gerektiği çünkü artan ultrasonik yoğunluğun ekstraksiyon 
verimini çok arttıracağı anlamına gelmediği rapor edilmiştir.

Ultrasonik reaktörlerin şekli ve boyutu: Ultrasonik dalgalar katı yüzeylerde yansıdığından dolayı ultrasonik banyo kullanılması durumunda; reaksiyon kabının şekli olduça önemlidir. Dalgaların en düşük düzeyde yansıması için en iyi seçim altı düz konik şekilde cam numune kaplarıyla çalışmaktır (Loimer and Mason, 1987). Numune kabinın duvar kalınlığı ultrason iletimini zayıflatmamak adına mümkün olduğunca minimum seviyede olmalıdır (Santos et al., 2009). Reaktör boyutlarının hesaplanması, maksimum verime ulaşmak ve ortama maksimum enerji transferini sağlamak için vericinin transdüsere göre konumu belirlenmelidir (Sun et al., 2011). Ultrasonik problar kullanıldığında hem dairesel hem de eksenel olarak yoğunluğun hızla azaldığ gözlemlenmektedir. Bu yüzden ultrasonik prob ile kap duvarı arasında, birbirlerine dokunmayacak şekilde minimum boşluk bırakılmalıdır (Santos et al., 2009). Ekstraksiyonda ultrasonik probun kullanılması durumunda prob şekli ve çapının ekstraksiyon üzerine etkili olabileceği düşünülmektedir. Probların çoğu isı ve korozyana karşı dayanıklı olmaları nedeniyle titanyum alaşımından üretilmektedir. Ancak zamanla aşınan probların kullanılması ekstraksiyon ortamına metal parçaların geçişine neden olmaktadır. Payreks ve kuartz malzeme kullanımının metallerin ortama iletimi problemini çözebileceği düşünülmektedir (Cravottoa et al., 2008).

\section{b. Ortam ile ilgili parametreler}

Ortam, ultrason yardımlı ekstraksiyon işleminin etkinliğinin artırılması için dikkate alınması gereken birçok unsuru içermektedir. Bu unsurlar aşağıda açıklanmıştır.

Çözgen: Ultrason yardımlı ekstraksiyon işleminde ekstraksiyon verimi üzerine, hedef metabolitlerin çözünürlüğünün yanı sıra çözücünün viskozite, yüzey gerilimi ve buhar basıncı gibi fiziksel parametrelerin de etkisi vardır. $\mathrm{Bu}$ fiziksel parametreler akustik kavitasyon üzerine etkilidir (Mason and Lorimer, 2002). Bir sıvıda kavitasyonun başlaması için gevşeme döngüsünde negatif basıncın sıvıyı oluşturan moleküller arasındaki koheziv kuvvetlerin üstesinden gelmesi gerekmektedir. Viskozite veya yüzey geriliminin artması moleküler etkileşimlerde artışa neden olarak kavitasyon eşiğini önemli ölçüde yükseltmektedir. Bu yüzden yüksek viskozieli sıvılarla çalışılırken genlik değeri yükseltilmelidir. Çünkü örnek viskozitesi artınca ultrasonik cihaz hareketine (örneğin prob ucu) karş1 örneğin direnci artmaktadır. Bu nedenle kavitasyonla sonuçlanacak gerekli mekanik titreşimleri elde edebilmek için yüksek yoğunluk (veya yüksek amplitüd değeri) önerilmektedir. Ultrason yardımlı ekstraksiyon işleminde yüksek buhar basıncına sahip çözücülere kıyasla kavitasyon kabarcıklarının çöküşü daha yoğun olduğundan düşük buhar basınçlı çözücüler tercih edilmektedir (Santos et al., 2009). Buhar basıncı sıvı ortamın sıcaklığına da bağlıdır.

Sıcaklık: Çözücü özelliklerini etkileyen en önemli faktörlerden biri de sıcaklıktır. Sıcaklık artışı viskozite ve yüzey geriliminde düşüşe sebep olurken; buhar basıncinı artırmaktadır. Buhar basıncinda meydana gelen artış ise, kabarcıklar içerisine daha fazla çözücü buharı girmesine neden olarak çok sayıda daha az şiddette çökecek kabarcıkların oluşumuna neden olacak ve dolayısıyla daha yüksek sıcaklıklarda sonikasyon etkisi azalacaktır (Santos et al., 2009). Bu nedenle düşük sıcaklık dereceleri tercih edilmekte ve genelde sıcaklık artışını sınırlandırmak için sıcaklık kontrolü yapılmaktadır (Sališová et al., 1997). Genellikle belli bir seviyeye kadar olan sıcaklık artışının ekstraksiyon verimini artırdığı bilinmektedir (Palma et al., 2013). Sonikasyon uygulanmamış örneklerle kıyaslandığında 20 ile $70^{\circ} \mathrm{C}$ arasındaki sıcaklık artışının ekstraksiyon verimini artırdığı bazı araştırmacılar tarfından rapor edilmektedir (Shirsath et al., 2012; Chemat et al., 2017). Bu etki, kavitasyon kabarcıklarının sayısının artması, çözücü-katı temas alanının daha fazla olması, çözgen difüzyonunun artması ve dolayısıyla istenen bileşiklerin hücre içinden çıkışı ve çözünürlüklerinin artmasına sebep olmaktadır. Bununla birlikte sıcaklık çözücünün kaynama noktasına yakın olduğu zaman bu etkinin azaldığı tespit edilirken aynı zamanda; çoğu araştırmaci $30^{\circ} \mathrm{C}$ 'nin altındaki düşük sıcaklığın verimlilik üzerine yararlı etkisini bildirmektedir (Palma and Barroso, 2002, Zhang et al., 2008; Esclapez et al., 2011). Sicaklığın hedef bileşiğe göre seçilmesi önemlidir (Zhang et al., 2009a; Zhang et al., 2009b). Dolayısıyla, sıcaklığa karşı hassas bileşiklerin bozulmasını önlemek için sıcaklık kontrolü gerekmektedir.

Çözünmüş gazların varlığı ve dış basınç: Ortamda gazların olmaması kavitasyon kabarcığ 1 oluşumunu zorlaştırmaktadır. Çünkü kavitasyon kabarcıkları sıvıda çözünmüş gazlardan oluşmaktadır (Pétrier et al., 2008). Çözünen gazlar çözücü içerisinde yeni kavitasyon kabarcıklarının oluşturulması için adeta çekirdek görevi üstlenmektedir (Mason and Lorimer, 2002; Leong et al., 2011). Genel olarak ekstraksiyon alanında çözücü içerisinde çözünmüş gaz bileşimi kontrol edilememektedir. Dış basıncın artması durumunda, kavitasyonu sağlamak için daha büyük bir akustik basınç gerekecektir. Ancak, kavitasyon eşiğine diş basıncın altında (>1atm) ulaşılırsa kavitasyon kabarcıklarının çöküş yoğunluğu basınçsız ortama göre daha yüksek olmakta ve dolayısıyla sonokimyasal etki artmaktadır (Santos et al., 2009; Leong et al., 2011). 
Matriks parametreleri: Ultrason yardıml ekstraksiyonun hedefi ve hedef moleküle bağlı olarak bitki matriksi taze (alg veya maya gibi) veya kuru (bitkiler, yağlı tohumlar gibi) olarak kullanılabilmektedir. Matrikse uygulanan ön işlemler oldukça önemlidir ve ekstraksiyon verimliliğini etkileyebilmektedir (Vinatoru, 2001). Hedef bileşenin çözünürlük ve stabilitesi ile seçilen çözücü ve sıvı ortam sicaklığı ekstraksiyon verimini etkilemektedir. Benzer şekilde, ekstraksiyon sistemi heterojen ve gözenekli bir ortam olduğundan kavitasyon kabarcıklarının boyutu da ekstraksiyon verimi üzerine etkilidir. Maddenin katı/sıvı oranı ve parçacık boyutu gibi diğer faktörler de ekstraksiyon etkinliği ile alakalıdır. Ekstraksiyon verimi; bitki materyalinin yapısı, esnekliği veya bileşim farklılıklarına bağlı olarak farklı derecelerde değişebilmektedir (Vilkhu et al., 2011).

\section{Ultrason yardımlı ekstraksiyonda kullanılan} ekipmanlar

Ultrason, farklı muamele şekillerine göre numuneler üzerinde doğrudan ve dolaylı olmak üzere iki farklı şekilde etki göstermektedir (Kek et al., 2013). Doğrudan etki, ses dalgasının direkt olarak numuneye etki etmesi ile görülürken; dolaylı etki ses dalgasının numuneye ulaşmadan önce ortamda bulunan kaplara ulaşması ile gerçekleşmektedir. Ultrasonik problar laboratuvarlarda yaygın kullanılan (Santos et al., 2007) cihazlardır. Bazı çalışmalar ultrasonik probun kullanılması durumunda kütle transferinde artış olduğunu göstermiştir (Legay et al., 2011). $\mathrm{Bu}$ artış ultrasonik dalgaların yayılması sürecinde herhangi bir engelle karşılaşmaksızın doğrudan numune ile temas etmesinden kaynaklanmaktadır (Capelo-Martínez, 2009). Ancak, ultrasonik probun uzun süreli kullanım sonucu korozyona uğraması (Wibetoe et al., 1999) ve sistemin açık olması durumunda uçucu bileşenlerin kaybı sistemin en büyük dezavantajidır. Problu sistemin dışında ultrasonik banyolar ise örnekler üzerine ultrasonun dolaylı olarak etki etmesini sağlamaktadırlar (Santos et al., 2007).

Problu ultrason cihazı ve ultrasonik banyoların her ikisinde de ultrasonik güç kaynağı olarak bir güç çevirici (transdüser) kullanılmaktadır. Piezoelektrik dönüştürücü, ultrasonik reaktörler içerisinde en yaygın kullanılan tiptir.

Ultrasonik banyo, en çok bilinen ve kullanılan ultrasonik cihaz türüdür. Genellikle bir veya daha fazla ultrasonik dönüştürücü ile paslanmaz çelik bir tanktan oluşmaktadır. Ultrasonik banyolar genellikle $40 \mathrm{kHz}$ civarı frekansta çalışmakta ve bir sıcaklık kontrol mekanizması ile donatılmaktadırlar. Oldukça ucuz ve kolay erişilebilir olmalarının yanı sıra çok sayıda örnek ile aynı anda çalışma imkânı sunmaktadırlar. Bununla birlikte problu sistem ile karşılaştırıldığında; numuneye direkt gönderilen düşük ultrason gücü sistemin dezavantajıdır. Sisteme verilen ultrasonik yoğunluk su ve analizde kullanılan cam malzemeler tarafindan zayıflatılmaktadır. Son zamanlarda ekstraksiyon uygulamaları için bu olumsuzlukların sınırlandırıldığ $25 \mathrm{kHz}$ 'de çalışan yeni banyo sistemleri geliştirilmiş̧ir. Bu banyolar, soğutma/ 1sıtma sistemleri sayesinde su dolaşımı ile sıcaklık kontrolünü sağlayan çift katmanlı bir manto ile donatılmış paslanmaz çelik bir reaktörden oluşmaktadırlar. Sistem, problu ultrason sistemine göre daha az verimlidir ancak, cihazın kullanım kolaylığı ve aynı anda birden fazla numuneyi işleme alma imkanı nedeniyle yaygın olarak kullanılmaktadır (Chemat et al., 2017)

Küçük hacimli ekstraksiyon uygulamalarında ultrasonik problar siklikla tercih edilen sistemlerdir. Prob sistemi ultrasonik banyolara kıyasla daha güçlüdür çünkü gönderilen ultrasonik yoğunluk küçük bir yüzeyden iletilmektedir. Genelde $20 \mathrm{kHz}$ civarında çalışmakta ve dönüştürücü reaktöre daldırılmış bir proba bağlanmaktadır. Böylece minimum enerji kayiplarıyla ekstraksiyon ortamına ultrasonun doğrudan iletimi sağlanmaktadır. Farklı uzunluk, çap ve uç şekillerine sahip prob çeşitleri mevcuttur. Prob seçimi uygulama ve numune hacmine göre yapılmaktadır. Prob tarafindan sıvı ortama iletilen ultrasonik yoğunluk reaktörde hizla sicaklık yükselmesine neden olmaktadır. Reaktörün çift ceketli bir soğutucu sistem ile soğutulması ekstraksiyon için gereklidir. $\mathrm{Bu}$ durum problu sistem için bir dezavantajdır (Vinatoru, 2015).

Son ylllarda ultrasonik ekstraksiyon tekniğinin soxhlet ekstraksiyonu ve distilasyon gibi klasik ekstraksiyon yöntemleri ile kombine edildiği yenilikçi teknolojiler de hızla geliştirilmektedir (Chemat et al., 2017).

\section{SONUÇ}

Bir bitkiden istenen bir bileşiğin ekstraksiyonunu gerçekleştirmek için kullanılacak tekniğin seçiminde; ekstraksiyon etkinliği ve tekrarlanabilirliği, uygulanan prosedürün kolaylığı, süre, maliyet ve güvenlik gibi parametrelerin tümü göz önünde bulundurulmalıdır. Öte yandan, biyoaktif bileşiklerin ve bu bileşiklerce zenginleştirilmiş fonksiyonel gidaların artan ekonomik değeri gelecekte daha ileri ekstraksiyon yöntemlerinin geliştirilmesini sağlayacaktır.

Günümüzde özellikle gıda, kozmetik ve ilaç endüstrileri açısından önemli olan biyoaktif bileşiklerin kazanımında yaygın olarak kullanılan ultrason yardımlı ekstraksiyon yöntemi; ultrasonik dalgalar yardımıyla bitki hücre duvarının bozunmasını sağlayan ve kütle transferini hızlandırarak istenen biyoaktif bileşenlerin klasik tekniklere kıyasla daha kısa sürede ve daha yüksek verimle elde edilmesini sağlayan bir uygulamadır. Ayrıca, daha düşük enerji 
sarfiyatı ve daha az çözgen kullanımı ile çevreci bir teknoloji olarak karşımıza çıkmaktadır. Son yıllarda ultrason yardımlı ekstraksiyonun yanı sira; enzim yardıml ekstraksiyon, mikrodalga yardımlı ekstraksiyon, vurgulu elektrik alanı yardımlı ekstraksiyon, süperkritik akış ekstraksiyonu ile basınçlı sıvı ekstraksiyonu gibi etkin yöntemlerin yanı sıra bu yöntemlerin klasik ekstraksiyon yöntemleri ile kombine halleri de kullanılmaktadır.

Ulusal ve uluslarası kuruluşlar tarafindan çevre düzenlemeleri çerçevesinde getirilen kısıtlama ve düzenlemeler ile desteklenen ve her geçen gün daha da geliştirilen 'yeşil ekstraksiyon teknikleri'sayesinde; daha az enerji sarfiyatı, maliyet ve süre ile daha güvenilir kimyasalların kullanıldığ1 yeni alternatif teknolojiler geliştirilecek ve gida sektörünün yanı sıra birçok farklı alanda kullanılabilecektir.

\section{KAYNAKLAR}

Ade-Omowaye, B.I.O., Angersbach, A., Taiwo, K.A., Knorr, D., 2001. Use of Pulsed Electric Field Pre-Treatment to İmprove Dehydration Characteristics of Plant Based Foods. Trends In Food Science and Technology, 12 (8): 285-295.

Alupului, A., 2012. Microwave Extraction of Active Principles From Medicinal Plants. U.P.B. Science Bulletin, Series B, 74 (2).

Angersbach, A., Heinz, V., Knorr, D., 2000. Effects of Pulsed Electric Fields on Cell Membranes in Real Food Systems. Innovative Food Science and Emerging Technologies, 1 (2): 135-149.

Asghari, J., Ondruschka, B., Mazaheritehrani, M., 2011. Extraction of Bioactive Chemical Compounds From the Medicinal Asian Plants by Microwave Irradiation. Journal of Medicinal Plants Research, 5 (4): 495-506.

Awad, T.S., Moharram, H.A., Shaltout, O.E., Asker, D., Youssef, M.M., 2012. Applications of Ultrasound İn Analysis, Processing and Quality Control of Food: A review. Food Research International, 48: 410-427.

Ashokkumar, M., 2011. The Characterization of Acoustic Cavitation Bubbles - An Overview, Ultrasonic Sonochemistry, 18: 864-872.

Azmir, J., Zaidul, I.S.M., Rahman, M.M., Sharif, K. M., Mohamed, A., Sahena, F., Jahurul, M.H.A., Ghafoor, K., Norulaini, N.A.N., Omar, A.K.M., 2013. Techniques for Extraction of Bioactive Compounds From Plant Materials: A Review. J. Food Eng., 117 (4): 426-436.

Barbero, G.F., Liazid, A., Palma, M., Barroso, C.G., 2008. Ultrasound-Assisted Extraction of Capsaicinoids From Peppers. Talanta, 75: 13321337.

Barsotti, L., Cheftel, J.C., 1998. Traitement Des Aliments Par Champs Electriques Pulses.
Science Des Aliments, 18: 584-601.

Benkerrou, F., Bey, M.B., Amrane, M., Louaileche, H., 2018. Ultrasonic-Assisted Extraction of Total Phenolic Contents from Phoenix dactylifera and Evaluation of Antioxidant Activity: Statistical Optimization of Extraction Process Parameters. Journal of Food Measurement and Characterization, 12 (3): 1910-1916.

Bermúdez-Aguirre, D., Mobbs, T., Barbosa-Cánovas, G., 2011. Ultrasound applications in food processing, In Ultrasound Technologies for Food and Bioprocessing. Feng, H., Barbosa-Canovas, G., Weiss, J. (eds). Springer, New York, USA, pp. 65-105.

Bhattacharjee, P., Singhal, R.S., Tiwari, S.R., 2006. Supercritical Carbon Dioxide Extraction of Cottonseed Oil. Journal of Food Engineering, 79 (3): 892-989.

Biesaga, M., 2011. Influence of Extraction Methods on Stability of Flavonoids. Journal of Chromatography A, 1218 (18): 2505-2512.

Bocevska, M., Sovov'A.H., 2007. Supercritical $\mathrm{CO}_{2}$ Extraction of Essential Oil from Yarrow, Journal of Supercritical Fluids, 40: 360-367.

Caldeira, I., Pereira, R., Clímaco, M.C., Belchior, A. and Bruno De Sousa, R., 2004. Improved Method for Extraction of Aroma Compounds in Aged Brandies and Aqueous Alcoholic Wood Extracts Using Ultrasound. Analytica Chimica Acta, 513: 125-134.

Caleja, C., Barros, L., Prieto, M.A., Barreiro, M.F., Oliveira, M.B.P.P. and Ferreira, I.C.F.R., 2017. Extraction of Rosmarinic Acid from Melissa officinalis L. by Heat-, Microwaveand Ultrasound-Assisted xtraction Techniques: A Comparative Study Through Response Surface Analysis. Separation and Purification Technology, 186: 297-308.

Canales, R., Guiñez, M., Bazán, C., Reta, M., Cerutti, S., 2017. Determining Heterocyclic Aromatic Amines in Aqueous Samples: A Novel Dispersive Liquid-Liquid Micro-Extraction Method Based on Solidification of Floating Organic Drop and Ultrasound Assisted Back Extraction Followed by UPLC-MS/MS. Talanta, 174: 548-555.

Capelo-Martıńez, J.L., Ximénez-Embún, P., Madrid, Y., Cámara, C., 2004. Advanced Oxidation Processes for Sample Treatment in Atomic Spectrometry. TrAC, Trends Anal. Chem., 23: 331-340.

Capelo-Martínez, J.L., 2009. Ultrasound in Chemistry: Analytical Applications, JohnWiley \& Sons.

Carrilloa, A.N., Aguilar-Santamaría, M.A., VernonCarter, E.J., Jiménez-Alvaradod, R., Cruz-Sosaa, 
F., Román-Guerrero, A., 2017. Extraction of Phenolic Compounds from Satureja Macrostema Using Microwave-Ultrasound Assisted and Reflux Methods and Evaluation of Their Antioxidant Activity and Cytotoxicity. Industrial Crops and Products, 103: 213-221.

Chemat, F., Rombaut, N., Sicaire, A.G., Meullemiestre, A., Fabiano-Tixier, A.S., AbertVian, M., 2017. Ultrasound Assisted Extraction of Food and Natural Products. Mechanisms, Techniques, Combinations, Protocols and Applications. A review. Ultrasonics Sonochemistry, 34: 540-560.

Chemat, F., Zill-e-Huma, Khan, M.K., 2011. Applications of Ultrasound in Food Technology: Processing, Preservation and Extraction. Ultrasonics Sonochemistry, 18 (4): 813-835.

Chen, F., Sun, Y., Zhao, G., Liao, X., Hu, X., Wu, J., Wang, Z., 2007. Optimization of UltrasoundAssisted Extraction of Anthocyanins in Red Raspberries and Identification of Anthocyanins in Extract Using High-Performance Liquid Chromatography-Mass Spectrometry. Ultrason. Sonochem., 14: 767-778.

Chen,S., Zeng,Z., Hu, N., Bai,B., Wang, H. and Suo, Y., 2018. Simultaneous Optimization of the Ultrasound-Assisted Extraction for Phenolic Compounds Content and Antioxidant Activity Oflycium ruthenicum Murr. Fruit Using Response Surface Methodology. Food Chemistry, 242: 1-8.

Chukwumah, Y.C., Walker, L.T., Verghese, M., Ogutu, S., 2009. Effect of Frequency and Duration of Ultrasonication on the Extraction Efficiency of Selected Isoflavones and TransResveratrol From Peanuts (Arachis hypogaea). Ultrasonic Sonochemistry, 16: 293-299.

Cocero, M.J., Gonzalez, S., Perez, S., Alonso, E., 2000. Supercritical Extraction of Unsaturated Products: Degradation of Beta Carotene Supercritical Extraction Processes, Journal of Supercritical Fluids, 19: 39-44.

Concha, J., Soto, C., Chamy, R., Zuniga, M.E., 2004. Enzymatic Pretreatment on Rosehip Oil Extraction: Hydrolysis and Pressing Conditions. Journal of American Oil Chemist's Society, 81 (6): 549-552.

Corbin, C., Fidel, T., Leclerc, E.A., Barakzoy, E., Sagot, N., Falguieres, A., Renouard, S., Blondeau, J.P., Ferroud, C., Doussot, J., Laine, E., Hano, C., 2015. Development and Validation of An Efficient Ultrasound Assisted Extraction of Phenolic Compounds From Flax (Linum usitatissimum L.) Seeds. Ultrasonic Sonochemistry, 26: 176-185.

Corralesa, M., Toepflb, S., Butza, P., Knorrc, D., Tauschera, B., 2008. Extraction of Anthocyanins
From Grape By-Products Assisted by Ultrasonics, High Hydrostatic Pressure or Pulsed Electric Fields: A Comparison. Innovative Food Science and Emerging Technologies, 9 (1): 8591.

Cravottoa, G., Boffaa, L., Mantegnaa, S., Peregob, P., Avogadrob, M., Cintasc, P., 2008. Improved Extraction of Vegetable Oils Under HighIntensity Ultrasound and/or Microwaves. Ultrasonics Sonochemistry, 15 (5): 898-902.

Dabre, R., Azad, N., Schwämmle, A., Lämmerhofer, M., Lindner, W., 2011. Simultaneous Separation and Analysis of Water-and Fat-Soluble Vitamins on Multi-Modal Reversed-Phase Weak Anion Exchange Material by HPLC-UV. J. Sep. Sci., 34: 761-772.

D'alessandro, L.G., Dimitrov, K., 2014. Kinetics of Ultrasound Assisted Extraction of Anthocyanins From Aronia melanocarpa (Black chokeberry) wastes. Chemical Engineering Research and Design, 92 (10): 1818-1826.

Delsart, C., Ghidossi, R., Poupot, C., Cholet, C., Grimi, N., Vorobiev, E., Milisic, V., Peuchot, M.M., 2012. Enhanced Extraction of Phenolic Compounds From Merlot Grapes By Pulsed Electric Field Treatment. American Journal of Enology and Viticulture, 63 (2): 205-211.

Demir, E, Serdar, G., Sökmen, M., 2015. Comparison of Some Extraction Methods for Isolation of Catechins and Caffeine From Turkish Green Tea. International Journal of Secondary Metabolite, 2 (2): 16-25.

Dhobi, M., Mandal, V., Hemalatha, S., 2009. Optimization of Microwave Assisted Extraction of Bioactive Flavolignan-Silybinin. Journal of Chemical Metrology, 3 (1): 13-23.

Dominguez, H., Ntiiiez, M.J., Lema, J.M., 1995. Enzyme-Assisted Hexane Extraction of Soybean Oil. Food Chemistry, 54 (2): 223-231.

EPA, 2017. http://www.epa.gov/greenchemistry/ pubs/about_gc.html. (Erişim Tarihi: 21 Aralık 2017).

Erdogan, S., Ates, B., Durmaz, G., Yilmaz, I., Seckin, T., 2011. Pressurized Liquid Extraction of Phenolic Compounds from Anatolia Propolis and Their Radical Scavenging Capacities. Food and Chemical Toxicology, 49 (7): 1592-1597.

Esclapez, M.D., García-Pérez, J.V., Mulet, A., Cárcel, J.A., 2011. Ultrasound-Assisted Extraction of Natural Products, Food Engineering Reviews, 3: 108-120.

Feng, H., Yang, W. 2011. Ultrasonic process. In Handbook on nonthermal processing Technologies (ed.) Daniel, F.F., Balasubramaniam, Zhang, H.,Ames, I.A; Wiley.

Fincan, M., De Vito, F., Dejmek, P., 2004. Pulsed Electric Field Treatment for Solid- Liquid 
Extraction of Red Beetroot Pigment. Journal of Food Engineering, 64 (3): 381-388.

Fincan, M., Dejmek, P., 2002. In Situ Visualization of the Effect of A Pulsed Electric Field on Plant Tissue. Journal of Food Engineering, 55 (3): 223-230.

Flint E.B., Suslick K.S., 1991. The Temperature of Cavitation, Science, 253: 1397-1399.

Ghafoor, K., Park, J., Choi, Y.H., 2010. Optimization of Supercritical Carbon Dioxide Extraction of Bioactive Compounds From Grape Peel (Vitis labrusca B.) by Using Response Surface Methodology. Innovative Food Science and Emerging Technologies, 11 (3): 485-490.

Gliszczy'nska-Swigło, A., Rybicka, I., 2015. Simultaneous Determination of Caffeine and Water-Soluble Vitamins ' In Energy Drinks by HPLC With Photodiode Array and Fluorescence Detection. Food Anal. Methods, 8: 139-146.

Gómez-García, R., Martínez-Ávila, G.C.G., Aguilar, C.N., 2012. Enzyme-Assisted Extraction of Antioxidative Phenolics From Grape (Vitis vinifera L.) Residues. 3 Biotech., 2 (4): 297-300.

González-Centeno, M.R., Knoerzer, K., Sabarez, H., Simal, S., Rosselló, C., Femenia, A., 2014. Effect of Acoustic Frequency and Power Density on the Aqueous Ultrasonic-Assisted Extraction of Grape Pomace (Vitis vinifera L.). A Response Surface Approach, Ultrason. Sonochem., 21: 2176-2184.

Guderjan, M., Töpfl, S., Angersbach, A., Knorr, D., 2005. Impact of Pulsed Electric Field Treatment on the Recovery and Quality of Plant Oils. Journal of Food Engineering, 67 (3): 281-287.

Hammi, K.M., Jdey, A., Abdelly, C., Majdoub, H., Ksouri, R., 2015. Optimization of UltrasoundAssisted Extraction of Antioxidant Compounds From Tunisian Zizyphus lotus Fruits Using Response Surface Methodology. Food Chemistry, 184: 80-89.

Handa, S.S, Khanuja, S.P.S., Longo, G., Rakesh, D.D., 2008. Extraction Technologies for Medicinal and Aromatic Plants. United Nations Industrial Development Organization and The International Centre for Science and High Technology. Icsunido Is Supported by the Italian Ministry of Foreign Affairs, 35-51.

Hanmoungjai, P., Pyle, D.L., Niranjan, K., 2001. Enzymatic Process for Extracting Oil and Protein From Rice Bran. Journal of The American Oil Chemists Society, 78 (8): 817-821.

Heinz, V., Toepfl, S., Knorr, D., 2003. Impact of Temperature on Lethality and Energy Efficiency of Apple Juice Pasteurization by Pulsed Electric Fields Treatment. Innovative Food Science and Emerging Technologies, 4 (2): 167-175.

Herrera, M.C., Luque De Castro, M.D., 2004.
Ultrasound-Assisted Extraction for the Analysis of Phenolic Compounds In Strawberries. Analytical and Bioanalytical Chemistry, 379 (78): 1106-1112.

Hossain, M.B., Brunton, N.P., Patras, A., Tiwari, B., O'donnell, C.P., Martindiana, A.B., Barry-Ryan, C., 2012. Optimization of Ultrasound Assisted Extraction of Antioxidant Compounds From Marjoram (Origanum majorana L.) Using Response Surface Methodology. Ultrasonic Sonochemistry, 19 (3): 582-590.

Ibañez, E., Herrero, M., Mendiola, J.A., CastroPuyana, M., 2012. Extraction and Characterization of Bioactive Compounds With Health Benefits From Marine Resources: Macro and Micro Algae, Cyanobacteria, and İnvertebrates. In: Hayes, M. (Ed.), Marine Bioactive Compounds: Sources, Characterization and Applications. Springer, pp. 55-98.

Inczedy, J., Lengyel, T., Ure, A.M., 1998. Supercritical Fluid Chromatography and Extraction. Compendium of Analytical Nomenclature (Definitive Rules 1997), Third Ed. Blackwell Science.

İçen, H., Gürü, M., 2010. Effect of Ethanol Content on Supercritical Carbon Dioxide Extraction of Caffeine From Tea Stalk and Fiber Wastes. Journal of Supercritical Fluids, 55 (1): 156-160.

İlbay, Z., 2016. Turunçgil Meyve ve Yapraklarının Farklı Ekstraksiyon Yöntemleriyle Ekstraksiyonu ve Matematik Modellemesi. İstanbul Üniversitesi, Fen Bilimleri Enstitüsü, Kimya Mühendisliği Anabilim Dalı, Temel İşlemler ve Termodinamik Bilim Dalı. Doktora Tezi, $168 \mathrm{~s}$.

Jadhav, D., Rekha, B.N., Parag, R.G., Virendra, K.R., 2009. Extraction of Vanillin From Vanilla Pods: A Comparison Study of Conventional Soxhlet and Ultrasound Assisted Extraction. Journal of Food Engineering, 93: 421-426.

Jain, T., 2009. Microwave Assisted Extraction for Phytoconstituents - An Overview. Asian Journal of Research in Chemistry, 2 (1): 19-25.

Joaquín-Cruz, E., Dueñas, M., García-Cruz, L., Salinas-Moreno, Y., Santos-Buelga, C., GarcíaSalinas, C., 2015. Anthocyanin and Phenolic Characterization, Chemical Composition and Antioxidant Activity of Chagalapoli (Ardisia compressak) Fruit: A Tropical Source of Natural Pigments. Food Research International, 70: 151-157.

Kavoura, D., Kyriakopoulou, K., Papaefstathiou, G., Spanidi, E., Gardikis, K., Loulia, V., Aligiannis, N., Krokida, M., Magoulasa, K., 2019. Supercritical $\mathrm{CO}_{2}$ extraction of Salvia fruticosa. The Journal of Supercritical Fluids 146: 159- 
164.

Kek, S., Chin, N., Yusof, Y., 2013. Direct and Indirect Power Ultrasound Assisted PreOsmotictreatments In Convective Drying of Guava Slices. Food Bioprod. Process., 91: 495506.

Kurek, M.A., Karp, S., Wyrwisz, J., Niu, Y.G., 2018. Physicochemical Properties of Dietary Fibers Extracted From Gluten-Free Sources: Quinoa (Chenopodium quinoa), Amaranth (Amaranthus caudatus) and Millet (Panicum miliaceum). Food Hydrocolloids, 85: 321-330.

Lang, Q., Wai, C.M., 2001. Supercritical Fluid Extraction in Herbal and Natural Product Studies A Practical Review. Talanta, 53 (4): 771-782.

Laroze, L., Soto, C., Zúñiga, M.E., 2010. Phenolic Antioxidants Extraction From Raspberry Wastes Assisted by-Enzymes. Electronic Journal of Biotechnology, 13 (6): 1-11.

Latif, S., Anwar, F., 2009. Physicochemical Studies of Hemp (Cannabis sativa) Seed Oil Using Enzyme-Assisted Cold-Pressing. European Journal of Lipid Science and Technology, 111 (10): 1042-1048

Lebovka, N.I., Bazhal, M.I., Vorobiev, E., 2002. Estimation of Characteristic Damage Time of Food Materials in Pulsed-Electric Fields. Journal of Food Engineering, 54 (4): 337-346.

Legay, M., Gondrexon, N., Le Person, S., Boldo, P., Bontemps, A., 2011. Enhancement of Heat Transfer by Ultrasound: Review and Recent Advances, Int. J. Chem. Eng.

Leong T., Ashokkumar M.S., 2011. Kentish, The Fundamentals of Power Ultrasound: A Review, Acoust. Aust., 39: 54-63.

Letellier, M., Budzinski, H., 1999. Microwave Assisted Extraction of Organic Compounds. Analusis, 27 (3): 259-270.

Luengo, E., Condon, S., Condon,S., Álvarez, I., Raso, J., 2014. Improving the Extraction of Carotenoids From Tomato Waste by Application of Ultrasound Under Pressure. Separation and Purification Technology, 136: 130-136.

Li, H., Chen, B., Yao, S., 2005. Application of Ultrasonic Technique for Extracting Chlorogenic Acid From Eucommia ulmodies Oliv. (E. Ulmodies). Ultrasonics Sonochemistry, 12 (4): 295-300.

Lorimer, J.P., Mason, T.J., 1987. Sonochemistry. Part 1 - The Physical Aspects. Chem. Soc. Rev. 16: 239-74.

López, N., Puértolas, E., Condón, S., Raso, J., Álvarez, I., 2009. Enhancement of the Extraction of Betanine From Red Beet Root by Pulsed Electric Fields. Journal of Food Engineering, 90 (1): 60-66.

Luthria, D.L., 2008. Influence of Experimental
Conditions on the Extraction of Phenolic Compounds From Parsley (Petroselinum crispum) Flakes Using a Pressurized Liquid Extractor. Food Chemistry, 107 (2): 745-752.

Ma, Y. Q., Chen, J. C., Liu, D. H., Ye, X.Q., 2009. Simultaneous Extraction of Phenolic Compounds of Citrus Peel Extracts, Effect of Ultrasound. Ultrasonics Sonochemistry, 16: 5762.

Ma, Y., Ye, X., Hao, Y., Xu, G., Xu, G., Liu, D., 2008. Ultrasound-Assisted Extraction of Hesperidin From Penggan (Citrus reticulata) Peel, Ultrasonic Sonochemistry, 15 (3): 227-232.

Machado, A.P.F, Pereira A., Barbero, G.F., Martínez, J., 2017. Recovery of Anthocyanins From Residues of Rubus fruticosus, Vaccinium myrtillus and Eugenia brasiliensis By Ultrasoundassisted Extraction, Pressurized Liquid Extraction and Their Combination. Food Chemistry, 231: 1-10.

Mackersie, J.W., Timoshkin, I.V., MacGregor, S.J., 2005. Generation of High-Power Ultrasound by Spark Discharges in Water. IEEE Trans. Plasma Sci., 33 (5): 1715-1724.

Maier, T., Göppert, A., Kammerer, D.R., Schieber, A., Carle, R., 2008. Optimization of a Process for Enzyme-Assisted Pigment Extraction From Grape (Vitis vinifera L.) pomace. European Food Research and Technology, 227 (1): 267-275.

Margulis, M.A., Margulis, I.M., 2003. Calorimetric Method for Measurement of Acoustic Power Absorbed in A Volume of A Liquid. Ultrasonic Sonochemistry, 10: 343-345.

Márquez-Sillero, I., Cárdenas, S., Valcárcel, M., 2013. Determination of Water-Soluble Vitamins in Infant Milk and Dietary Supplement Using a Liquid Chromatography On-Line Coupled to A Corona-Charged Aerosol Detector. J. Chromatogr. A, 1313: 253-258.

Mason, T.J., 1990. Chemistry With Ultrasound, Elsevier Applied Science, New York.

Mason, T.J., Cobley, A.J., Graves, J.E., Morgan, D., 2011. New Evidence for the Inverse Dependence of Mechanical and Chemical Effects on the Frequency of Ultrasound, Ultrasonic Sonochemistry, 18: 226-230.

Mason, T.J., Lorimer, J.P., 2002. General principles, In Applied Sonochemistry: Uses of Power Ultrasound in Chemistry and Processing, Mason, T.J., Lorimer J.P. (eds), Wiley-Vch Verlag, Germany, pp. 25-74.

Mroczek, T., Mazurek, J., 2009. Pressurized Liquid Extraction and Anticholinesterase ActivityBased Thin-Layer Chromatography With Bioautography of Amaryllidaceae Alkaloids. Analytica Chimica Acta, 633 (2): 188-196.

Nieto, A., Borrull, F., Pocurull, E., Marcé, R.M., 2010. 
Pressurized Liquid Extraction: A Useful Technique to Extract Pharmaceuticals and Personal-Care Products From Sewage Sludge. Trac Trends In Analytical Chemistry, 29 (7): 752-764.

Nipornram, S., Tochampa, W., Rattanatraiwong, P., 2018. Optimization of Low Power UltrasoundAssisted Extraction of Phenolic Compounds From Mandarin (Citrus reticulata Blanco Cv. Sainampueng) Peel. Food Chemistry, 241: 338345.

Niranjan, K., Hanmoungjai, P., 2004. Enzyme-aided aquous extraction. In Nutritionally Enhanced Edible Oil Processing. Dunford, N.T., Dunford, H.B. (eds), Aocs Publishing.

Palma, M., Barbero, G.F., Pineiro, Z., Liazid, A., Barroso, C.G., Rostagno, M.A., Prado, J.M., Meireles, M.A.A., 2013. Natural Product Extraction: Principles and applications, Chapter 2: Extraction of natural products: principles and fundamental aspects, In: Rostagno, M.A., Prado, J.M. (eds), The Royal Society of Chemistry, UK, pp. 58-88.

Palma, M., Barroso, C.G., 2002. Ultrasound-Assisted Extraction and Determination of Tartaric and Malic Acids From Grapes and Winemaking byProducts. Analytica Chimica Acta, 458: 119130.

Pan, X., Niu, G., Liu, H., 2003. Microwave-Assisted Extraction of Tea Polyphenols and Tea Caffeine From Green Tea Leaves. Chemical Engineering and Processing, 42 (2): 129-133.

Pétrier, C., Gondrexon, N., Boldo, P., 2008. Ultrasons Et Sonochimie, Techniques De L'ingénieur Chimie Verte: Optimisation Des Modes De Séparation. D'activation Et De Synthèse Base Documentaire: T1b493duo.

Picó, Y. 2013. Ultrasound-Assisted Extraction for Food and Environmental Samples. Trends in Analytical Chemistry, 43: 84-99.

Pinela, J., Prieto, M.A., Pereira, E., Jabeur, I., Barreiro, M.F., Barros, L., Ferreira, I.J.F.R., 2019. Optimization of Heat and UltrasoundAssisted Extraction of Anthocyanins from Hibiscus sabdariffa Calyces for Natural Food Colorants. Food Chemistry, 275: 309-321.

Pingret, D., Fabiano-Tixier, A.S., Chemat, F., 2013. Chapter 3: Ultrasound-Assisted Extraction. In natural product extraction: Principles and applications. Rostagno, M.A., Prado, J.M. (eds).The Royal Society of Chemistry, UK, pp. 89-112.

Ponmurugan, K., Al-Dhabi N.A., Maran, J.P., Karthikeyan, K., Moothy, I.G., Sivarajasekar, N., Manoj, J.J.B., 2017. Ultrasound Assisted Pectic Polysaccharide Extraction and Its Characterization From Waste Heads of
Helianthus annus. Carbohydrate Polymers, 173: 707-713.

Poongothai, S., Ilavarasan, R., Karrunakaran, C.M., 2010. Simultaneous and Accurate Determination of Vitamins B1, B6, B12 and Alpha-Lipoic Acid in Multivitamin Capsule by Reverse-Phase High Performance Liquid Chromatographic Method. Int. J. Pharm. Pharm. Sci., 2: 133-139.

Puértolas, E., López, N., Saldaña, G., Álvarez, I., Raso, J., 2010. Evaluation of Phenolic Extraction During Fermentation of Red Grapes Treated by A Continuous Pulsed Electric Fields Process at Pilot-Plant Scale. Journal of Food Engineering, 119 (3): 1063-1070.

Puri, M., Sharma, D., Barrow, C.J., 2012. EnzymeAssisted Extraction of Bioactives From Plants. Trends in Biotechnology, 30 (1): 37-44.

Richter, B.E., Jones, B.A., Ezzell, J.L., Porter, N.L., Avdalovic, N., Pohl, C., 1996. Accelerated Solvent Extraction: A Technology for Sample Preparation. Analytical Chemistry, 68 (6): 10331039.

Rodsamrana, P., Sothornvita, R., 2019. Extraction of Phenolic Compounds from Lime Peel Waste Using Ultrasonicassisted and MicrowaveAssisted Extractions. Food Bioscience, 28: 6673.

Rosenthal, A., Pyle, D.L., Niranjan, K., 1996. Aqueous and Enzymatic Processes for Edible Oil Extraction. Enzyme Microbial Technology, 19 (6): 402-420.

Rosenthal, A., Pyle, D.L., Niranjan, K., Gilmour, S., Trinca, L., 2001. Combined Effect of Operational Variables and Enzyme Activity on Aqueous Enzymatic Extraction of Oil and Protein From Soybean. Enzyme and Microbial Technology, 28 (6):499-509.

Rostagno, M.A., Palma, M., Barroso, C.G., 2004. Pressurized Liquid Extraction of İsoflavones From Soybeans. Analytica Chimica Acta, 522 (2): 169-177.

Salar Bashi, D., Mortazavi, S.A., Rezaei, K., Rajaei, A., Karimkhani, M.M., 2012. Optimization of Ultrasound-Assisted Extraction of Phenolic Compounds From Yarrow (Achillea beibrestinii) by Response Surface Methodology. Food Science and Biotechnology, 21 (4): 1005-1011.

Sališová, M., Toma, ড̌., Mason, T.J., 1997. Comparison of Conventional and Ultrasonically Assisted Extractions of Pharmaceutically Active Compounds From Salvia officinalis, Ultrasonic Sonochemistry, 4: 131-134.

Santos, D.C.M.B., Carvalho, L.S.B., Lima,D.C., Leão, D.J., Teixeira, L.S.G., Gracas, M., 2017. Korndetermination of Micronutrient inerals in Coconut Milk by ICP-OES After UltrasoundAssisted Extraction Procedure. Journal of Food 
Composition and Analysis, 34(1): 75-80.

Santos, H.M., Capelo, J.L., 2007. Trends in Ultrasonic-Based Equipment for Analytical Sample Treatment. Talanta, 73: 795-802.

Santos, H.M., Lodeiro, C., Capelo-Martínez, J.L., 2009. The Power of Ultrasound, In: CapeloMartínez J. L. (Ed.), Ultrasound in chemistry: Analytical applications, Wiley-Vch Verlag, Germany, pp. 1-16.

Santos, K.A., Gonçalves, J.E., Cardozo-Filho, L., da Silva, E.A., 2019. Pressurized Liquid and Ultrasound-Assisted Extraction of A-Bisabolol from Candeia (Eremanthus erythropappus) Wood. Industrial Crops and Products, 130: 428435 .

Sharma, A., Khare, S.K., Gupta, M.N., 2002. EnzymeAssisted Aqueous Extraction of Peanut Oil. Journal of American Oil Chemist's Society, 79 (3): 215-218.

Shen, J., Shao, X., 2005. A Comparison of Accelerated Solvent Extraction, Soxhlet Extraction, and Ultrasonic-Assisted Extraction for Analysis of Terpenoids and Sterols in Tobacco. Analytical and Bioanalytical Chemistry, 383 (6): 1003-1008.

Shen,Y., Zhang,X., Prinyawiwatkul, W., Xu, Z., 2014. Simultaneous Determination of Red and Yellow Artificial Food Colourants and Carotenoid Pigments in Food Products. Food Chemistry, 157: 553-558.

Shirsath, S.R., Sonawane, S.H., Gogate, P.R., 2012. Intensification of Extraction of Natural Products Using Ultrasonic Irradiations-A Review of Current Status. Chemistry of Engineering Process, 53: 10-23.

Sihvonen, M., Järvenpää, E., Hietaniemi, V, Huopalahti, R., 1999. Advances in Supercritical Carbon Dioxide Technologies. Trends in Food Science and Technology, 10 (6-7): 217-222.

Singh, R.K., Sarker, B.C., Kumbhar, B.K., Agrawal, Y.C., Kulshreshtha, M.K., 1999. Response Surface Analysis of Enzyme-Assisted Oil Extraction Factors for Sesame, Groundnut, and Sunflower Seeds. Journal of Food Science and Technology, 36 (6): 511-514.

Sivakumar, V., Lakshmi, A.J., Vijayeeswaree, J., Swaminathan, G., 2009. Ultrasound Assisted Enhancement in Natural Dye Extraction From Beetroot forIndustrial Applications and Natural Dyeing of Leather. Ultrasonics Sonochemistry, 16: 782-789.

Sun, Y., Liu, D., Chen, J., Ye, X., Yu, D., 2011. Effects of Different Factors of Ultrasound Treatment on the Extraction Yield of the AllTrans- $\beta$-Carotene From Citrus Peels. Ultrasonic Sonochemistry, 18: 243-249.

Suslick, K.S., 1989. The chemical effects of ultrasound, Sci. Am. 260: 80-86.

Suslick, K.S., Didenko, Y., Fang, M.M., Hyeon, T., Kolbeck, K.J., Mcnamara, W.B., Mdleleni, M. M., Wong, M., 1999. Acoustic Cavitation and Its Chemical Consequences. Philosophical Transactions of the Royal Society of London, Ser. A, 357: 335-353.

Suslick, K.S., Eddingsaas, N.C., Flannigan, D.J., Hopkins, S.D., Xu, H., 2011. Extreme Conditions During Multibubble Cavitation: Sonoluminescence As A Spectroscopic Probe. Ultrasonic Sonochemistry, 18: 842-846.

Temelli, F., Güçlü-Üstündag, Ö., 2005. Supercritical Technologies for Further Processing of Edible Oils. Bailey's Industrial Oil and Fat Products. John Wiley \& Sons, Inc.

Tiwari, B.K., 2015. Ultrasound: A Clean, Green Extraction Technology, TrAC Trends in Analytical Chemistry, 71: 100-109.

Toepfl, S., Mathys, A., Heinz, V., Knorr, D., 2006. Review: Potential of High Hydrostatic Pressure and Pulsed Electric Fields for Energy Efficiency and Environmentally Friendly Food Processing. Food Review International, 22 (4): 405-423.

Toma, M., Vinatoru, M., Paniwnyk, L., Mason, T.J., 2001. Investigation of the Effects of Ultrasound on Vegetal Tissues During Solvent Extraction. Ultrasonic Sonochemistry, 8: 137-142.

Velickovic, V., Durovic, S., Radojkovic, M., 2017. Application of Conventional and NonConventional Extraction Approaches for Extraction of Erica carnea L.: Chemical Profile and Biological Activity of Obtained Extracts. Journal of Supercritical Flu1ds, 128: 331-337.

Vilkhu, K., Manasseh, R., Mawson, R., Ashokkumar, M., 2011. Ultrasonic recovery and modification of food ingredients, In Ultrasound Technologies for Food and Bioprocessing. Feng, H., BarbosaCanovas, G., Weiss J. (eds). Springer, New York, USA, pp. 345-368.

Vilkhu, K., Mawson, R., Simons, L., Bates, D., 2008. Applications and Opportunities for Ultrasound Assisted Extraction in the Food Industry-A Review. Innovative Food Science Emerging Technology, 9: 161-169.

Vinatoru, M., 2015. Ultrasonically Assisted Extraction (UAE) of Natural Products Some Guidelines for Good Practice and Reporting, Ultrason. Sonochem., 25: 94-95.

Vinatoru, M., 2001. An Overview of Ultrasonically Assisted Extraction of Bioactive Principles From Herbs. Ultrasonic Sonochemistry, 8: 303-313.

Vinatoru, M., Mason, T.J., Calinescu, I., 2017. Ultrasonically Assisted Extraction (UAE) and Microwave Assisted Extraction (MAE) of Functional Compounds From Plant Materials. Trends In Analytical Chemistry, 97: 159-178. 
Virot, M., Tomao, V., Le Bourvellec, C., Renard, M.C.G.C., Chemat F., 2010. Towards the Industrial Production of Antioxidants From Food Processing By-Products With UltrasoundAssisted Extraction. Ultrasonics Sonochemistry, 17: 1066-1074.

Vorobiev, E., Jemai, A.B., Bouzrara, H., Lebovka, N.I., Bazhal, M.I., 2005. Pulsed Electric Field Assisted Extraction of Juice from Food Plants. In Novel Food Processing Technologies. BarbosaCanovas, G., Tapia, M.S., Cano, M.P. (eds). Crc Press, New York, pp. 105-130.

Vorobiev, E., Lebovka, N.I., 2006. Extraction of intercellular components by pulsed electric fields. In: Pulsed Electric Field Technology for the Food Industry. Raso, J., Heinz, V. (eds). Fundamentals and Applications. Springer, New York, pp. 153-194.

Wang, L., Weller, C.L., 2006. Recent Advances in Extraction of Nutraceuticals From Plants. Trends In Food Science \& Technology, 17 (6): 300-312.

Wang, W., Chen, W., Zou, M., Lv, R., Wang, D., Hou, F., Feng, H., Maa, X., Zhong, J., Tian D., Ye, X., Liu, D., 2018. Applications of Power Ultrasound in Oriented Modification and Degradation of Pectin: A Review. Journal of Food Engineering, 234: 98-107.

Wang, W., Ma, X., Xu, Y., Cao, Y., Jiang, Z., Ding, T., Ye, X., Liu, F.X., 2015. Ultrasound Assisted Extraction of Pectin From Grapefruit Peel: Optimization and Comparison with the Conventional Method. Food Chemistry, 178: 106-114.

Wei, E., Yang, R., Zhao, H., Wang, P., Zhao, S., Zhai, W., Zhang, Y., Zhou, H., 2019. MicrowaveAssisted Extraction Releases the Antioxidant Polysaccharides From Seabuckthorn (Hippophae rhamnoides L.) Berries. International Journal of Biological Macromolecules, 123: 280-290.

Wen, C., Zhang, J., Zhang, H., Dzah, C.S., Zandile, M., Duan, Y., Ma, H., Luo, X., 2018. Advances in Ultrasound Assisted Extraction of Bioactive Compounds From Cash Crops. UltrasonicsSonochemistry, 48: 538-549.

Wibetoe, G., Takuwa, D.T., Lund, W., Sawula, G., 1999. Coulter Particle Analysis Used Forstudying the Effect of Sample Treatment in Slurry Sampling Electrothermal Atomicabsorption Spectrometry. Fresenius' J. Anal. Chem., 363: 46-54.

Xia, T., Shi, S., Wan, X., 2006. Impact of UltrasonicAssisted Extraction on the Chemical and Sensory Quality of Tea Infusion. Journal of Food Engineering, 74: 557-560.

Xu, D.P., Zheng, J., Zhou, Y., Li, Y., Li,S., Li, H.B.,
2017. Ultrasound-Assisted Extraction of Natural Antioxidants From the Flower of Limonium sinuatum: Optimization and Comparison with Conventional Methods Food Chemistry, 217: 552-559.

Xu, X., Dong, J., Mu, X., Sun, L., 2011. Supercritical $\mathrm{CO}_{2}$ Extraction of Oil, Carotenoids, Squalene and Sterols From Lotus (Nelumbo nucifera Gaertn) Bee Pollen. Food and Bioproducts Processing, 89: 47-52.

Yang, X., Li, Y., Li, S., Oladejo, A.O., Wang,Y., Huang, S., Zhou, C., Ye, X., Ma, H., Duan, Y., 2018. Effects of Ultrasound-Assisted $\alpha$-Amylase Degradation Treatment With Multiple Modes on the Extraction of Rice Protein. Ultrasonics Sonochemistry, 40: 890-899.

Yang, Y., Zhang, F., 2008. Ultrasound-Assisted Extraction of Rutin and Quercetin From Euonymus alatus (Thunb.) Sieb. Ultrasonics Sonochemistry, 15 (4): 308-313.

Yolmeh, M., Najafi, M.B.H., Farhoosh, R. 2014. Optimisation of Ultrasound-Assisted Extraction of Natural Pigment From Annatto Seeds by Response Surface Methodology (RSM). Food Chemistry, 155: 319-324.

Zhang H.F., Yang X.H., Zhao L.D., Wang, Y., 2009a. Ultrasonic-Assisted Extraction of Epimedin C From Fresh Leaves of Epimedium and Extraction Mechanism. Innovative Food Science Emerging Technology, 10: 54-60.

Zhang Q.A., Zhang Z.Q., Yue X.F., Fan X.H., Li T., Chen S.F., 2009b. Response Surface Optimization of Ultrasound-Assisted Oil Extraction From Autoclaved Almond Powder. Food Chemistry, 116: 513-518.

Zhang Z.S., Wang L.J., Li, D., Jiao, S.S., Chen, X.D., Mao Z.H., 2008. Ultrasound Assisted Extraction of Oil From Flaxseed. Seperation and Purification Technology, 62: 192-198.

Zhang, Q.A., Wang, T.T., 2017. Effect of Ultrasound Irradiation on the Evolution of Color Properties and Major Phenolic Compounds In Wine During Storage. Food Chemistry, 234: 372-380.

Zhao, L.I., Zhao, G., Chen, F., Wang, Z., Wu, J., Hu, X., 2006. Different Effects of Microwave and Ultrasound on the Stability of (All-E)Astaxanthin. Journal of Agricultural Food Chemistry, 54 (21): 8346-8351.

Zhu, Z., Wu, Q., Di, X., Li, S., Barba, F.J., Koubaa, M., Roohinejad, S., Xiong, X., He, J., 2017. Multistage Recovery Process of Seaweed Pigments: Investigation of Ultrasound Assisted Extraction and Ultra-Filtration Performances. Food and Bioproducts Processing, 104: 40-47. 